\title{
Retrieving simulated volcanic, desert dust and sea-salt particle properties from two/three-component particle mixtures using UV-VIS polarization lidar and T matrix
}

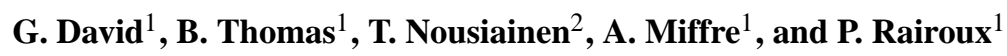 \\ ${ }^{1}$ Institut Lumière Matière, UMR5306 Université Lyon 1, CNRS, Université de Lyon, 69622 Villeurbanne cedex, France \\ ${ }^{2}$ Department of Physics, P.O. Box 48, 00014, University of Helsinki, Finland
}

Correspondence to: A. Miffre (alain.miffre@univ-lyon1.fr)

Received: 21 December 2012 - Published in Atmos. Chem. Phys. Discuss.: 17 January 2013

Revised: 6 June 2013 - Accepted: 7 June 2013 - Published: 18 July 2013

\begin{abstract}
During transport by advection, atmospheric nonspherical particles, such as volcanic ash, desert dust or seasalt particles experience several chemical and physical processes, leading to a complex vertical atmospheric layering at remote sites where intrusion episodes occur. In this paper, a new methodology is proposed to analyse this complex vertical layering in the case of a two/three-component particle external mixtures. This methodology relies on an analysis of the spectral and polarization properties of the light backscattered by atmospheric particles. It is based on combining a sensitive and accurate UV-VIS polarization lidar experiment with T-matrix numerical simulations and air mass back trajectories. The Lyon UV-VIS polarization lidar is used to efficiently partition the particle mixture into its nonspherical components, while the T-matrix method is used for simulating the backscattering and depolarization properties of nonspherical volcanic ash, desert dust and sea-salt particles. It is shown that the particle mixtures' depolarization ratio $\delta_{\mathrm{p}}$ differs from the nonspherical particles' depolarization ratio $\delta_{\text {ns }}$ due to the presence of spherical particles in the mixture. Hence, after identifying a tracer for nonspherical particles, particle backscattering coefficients specific to each nonspherical component can be retrieved in a two-component external mixture. For three-component mixtures, the spectral properties of light must in addition be exploited by using a dualwavelength polarization lidar. Hence, for the first time, in a three-component external mixture, the nonsphericity of each particle is taken into account in a so-called $2 \beta+2 \delta$ formalism. Applications of this new methodology are then demonstrated in two case studies carried out in Lyon, France, related
\end{abstract}

to the mixing of Eyjafjallajökull volcanic ash with sulfate particles (case of a two-component mixture) and to the mixing of dust with sea-salt and water-soluble particles (case of a three-component mixture). This new methodology, which is able to provide separate vertical profiles of backscattering coefficient for mixed atmospheric dust, sea-salt and watersoluble particles, may be useful for accurate radiative forcing assessments.

\section{Introduction}

Atmospheric particles play an important role in the Earth's radiative budget and climate (Ramaswamy et al., 2001). Quantifying their effect is a challenging task, in part due to the complexity of these atmospheric particles, which present a wide range of sizes, shapes and chemical compositions with interconnected distributions, as we recently published in a comprehensive study (Dupart et al., 2012). Nonspherical particles are particularly challenging because there is no generic, exact light-scattering theory for such particles (Mishchenko et al., 2000; Kahnert 2003). The particle nonsphericity is known to have a major impact on both lidar and satellite remote sensing retrievals (Mishchenko et al., 1995; Winker et al., 2009, 2010; Vernier et al., 2011), and remote sensing is a major source of global data on aerosol particle distributions, needed in radiative and climate forcing assessments. Hence, the lack of knowledge on volcanic ash, desert dust and sea-salt particles induces large uncertainties in the Earth's climate. These particles may remain in the 
troposphere for several weeks (Robock, 2000; Overnevaidte et al., 2009), which further reinforce their radiative impact. During transport by advection from source regions to places where intrusion episodes occur, the particle properties may also change due to processes, such as sedimentation, mixing with other particles (Zhang, 2008), hygroscopic growth and possible chemical alteration (Riccobono et al., 2011; Bourcier et al., 2011). After long-range transport, these particles are hence highly dispersed and aged, and may present sizes or shapes different from those observed in the source region. One of the typical consequences is a complex vertical layering generally observed in the low troposphere at far-range remote sites far from their source regions.

Lidar remote sensing is a powerful instrument to provide vertical profiles of particles' backscattering and extinction properties in the atmosphere. As explained by Mishchenko et al. (2002), atmospheric nonspherical particles can be detected by their ability to depolarize laser light by using a single laser wavelength ( $1 \lambda$ polarization lidar experiment) or several (for example, $2 \lambda$ polarization lidar experiment), as stated in Sugimoto et al. (2002), Sassen et al. (2007), Gasteiger et al. (2011), Miffre et al. (2011), Di Girolamo et al. (2012), and David et al. (2012). Typically, depolarization measurements are often performed at visible (VIS) and infrared (IR) spectral ranges (Sugimoto et al., 2002; Winker et al., 2009; Freudenthaler et al., 2009; Ansmann et al., 2011). As shown by David et al. (2012), a precise design and optimization of the lidar detector is needed to efficiently reduce possible systematic biases and to achieve sensitive and accurate particle UV polarization lidar measurements. Absolute particle UV depolarization ratios as low as $6 \times 10^{-3}$, close to the UV molecular depolarization, can hence be measured after precise polarization calibration (Alvarez et al., 2006) and significant solar background reduction (David et al., 2012). To complement these experimental studies, optical properties of nonspherical particles can be computed using simple (Nousiainen and Vermeulen, 2003; Dubovik et al., 2006; Nousiainen et al., 2006; Wiegner et al., 2009; Veselovskii et al., 2010) or more complex shapes (Nousiainen et al., 2012; Lindqvist et al., 2011). In addition, optical properties can be measured in a laboratory, such as those for volcanic ash (Muñoz et al., 2004), desert dust (Volten et al., 2001) and sea-salt particles (Sakaï et al., 2010).

Depolarization of light by atmospheric nonspherical particles is of particular interest in the case of long-range transport, where the dependence of the depolarization on the wavelength has to be characterized (Wiegner et al., 2011) and fewer studies have been performed. During long-range transport, different multi-component mixtures of atmospheric particles may form the following:

- Two-component particle mixture: an example of this mixture is given by the recent eruption of the Eyjafjallajökull volcano, where volcanic ash particles mixed with spherical sulfate particles.
- Three-component particle mixtures: such a mixture is observed, for example, after Saharan dust outbreaks when nonspherical sea-salt particles mix with desert dust particles and water-soluble species. Another example is given by the 2011 eruption of the Eritrean Nabro volcano, where volcanic ash particles encountered desert dust particles in the troposphere while also water-soluble particles were present.

In such situations, for radiative forcing assessments, the particle nonsphericity of sea-salt, desert dust and volcanic ash particles should be taken into account. "Two-component particle mixtures" were first studied by Shimizu et al. (2004), who separated dust from non-dust particles using a $1 \lambda$ polarization lidar system. This methodology was applied by Tesche et al. (2009) to address the particle extinction at Raman channels and further developed by Ansmann et al. (2012), assuming coarse particles (with diameter above $1 \mu \mathrm{m})$ to depolarize laser light while fine particles were assumed spherical (with diameter below $1 \mu \mathrm{m}$ ), a questionable assumption since dust particles as small as $200 \mathrm{~nm}$ in diameters were measured during the SAMUM field campaign (Kaaden et al., 2009). Marenco and Hogan (2011) also analysed two-component particle mixtures (note they called their method three-component atmosphere approach as they actually include air molecules as one component). "Three-component particle mixtures" have been studied by Nishizawa et al. (2011), who considered nonspherical dust particles mixed with sea-salt and water-soluble particles with a $1 \lambda$ polarization lidar experiment to derive the particles extinction. They assumed sea-salt particles to be spherical, which may not be the case, as first shown by Murayama et al. (1999). Hence, to our knowledge, $2 \lambda$ polarization lidar experiments have only been used to observe two-component particle mixtures (Sugimoto and Lee, 2006; Tesche et al., 2009).

In this Special Issue on the depolarization of light by atmospheric particles, polarization lidar measurements have been performed on polar stratospheric clouds (Córdoba-Jabonero et al., 2013), and numerical simulations are proposed to study the depolarization of light by ice cylinders (Nicolet et al., 2012), while laboratory measurements have been performed to study small ice crystals (Schnaiter et al., 2012) and dust particles (Glen et al., 2013). Our contribution, dedicated to the polarization $(\pi)$ and spectral $(\lambda)$ properties of atmospheric nonspherical particles after long-range transport, combines $2 \lambda$ polarization lidar measurements with numerical light-scattering simulations. The goal of this paper is to show what is objectively retrievable when combining these two methodologies, as opposed to comparing both approaches separately, as is often presented in the literature. The numerical simulations are used to specifically address nonspherical particles in the two/three-component particle mixture. For the first time, a three-component particle mixture, to be chosen between volcanic ash, desert dust, sea-salt or water- 
soluble particles, is partitioned by using a $2 \lambda$ polarization lidar (development of a $2 \beta+2 \delta$ algorithm) to take into account the particle nonsphericity within each component. We present a new methodology to retrieve range-resolved vertical profiles of atmospheric particles' backscattering coefficient specific to each particle component, and demonstrate its performance for two case studies. Our methodology does not allow identifying particles types as a chemical analysis would then be required. It however gives vertical profiles of particle backscattering coefficient that are specific to each assumed particle component, with an accuracy that depends on the accuracy of the single-scattering properties we assigned for the different particles components (ash, dust, sea salt). The information on backscattering and polarization in itself is valuable for use in radiative forcing and climate models. The coupling of lidar with inelastic Raman scattering (Müller et al., 2001) or with passive remote sensing (Dubovik et al., 2006; Boyouk et al., 2010) has not been considered in this paper. A precise chemical analysis has not been performed during the experiments carried out, because it is well beyond the scope of this contribution. Instead, we used 7-day air mass back trajectories to identify the potential source of the nonspherical particles present at the remote site. Otherwise, we already published in Dupart et al. (2012) on the combined use of our lidar depolarization experiment with laboratory chemical studies.

The paper is organized as follows. The $2 \lambda$ polarization lidar experiment is described in Sect. 2, where the retrieval of polarization-resolved particle backscattering profiles is described, with emphasis on error analysis. The backscattering and depolarization properties of ash-, dust- and sea-salt-like particles are computed in Sect. 3 through controlled singlescattering numerical simulations on these nonspherical particles. Our new methodology is then presented in Sect. 4, with separate treatments for the two and the three-component mixtures. Starting from the scattering matrix formalism (see Appendix A), we explore the impact of spherical (s) particles, present after long-range transport (I. Veselovskii et al., 2010), which contribute to the observed depolarization ratio $\delta_{\mathrm{p}}$ of the particle mixture. A tracer for nonspherical (ns) particles is then identified for the two/three-component particle mixture. In Sect. 4 , we describe how to combine the $2 \lambda$ polarization lidar measurements with the computed optical properties to retrieve ns-particle backscattering coefficient for each component in two- and three-component particle mixtures. Section 5 is dedicated to the application of this new methodology in two case studies: (i) the possible mixing of Eyjafjallajökull volcanic ash particles with spherical sulfate particles over Lyon (France) as an example of a "two-component particle mixture", and (ii) the possible mixing of desert dust with sea-salt and water-soluble particles as an example of a "three-component particle mixture", observed during a longrange Saharan dust outbreak, which occurred over Lyon in October 2011. For the first time, both sea-salt and dust particles are treated as nonspherical, which is justified due to the observed low relative humidity and the accuracy of our $2 \lambda$ polarization measurement. We believe this new methodology may be used for deriving particle distributions necessary for precise radiative forcing assessments as well as for validating satellite retrievals. The paper ends with a conclusion and outlooks.

\section{UV-VIS polarization lidar remote sensing experiment}

\subsection{Lyon lidar experimental set-up}

Our dual-wavelength polarization lidar set-up has been extensively described in David et al. (2012), where the design, the optimization and the performance of this home-built setup are detailed. The Lyon polarization lidar is composed of a doubled and tripled Nd:YAG laser emitting 10 ns-laser pulses at $\lambda_{1}=355$ and $\lambda_{2}=532 \mathrm{~nm}$ wavelength with $10 \mathrm{~mJ}$ of energy and a high degree of linear polarization (10000:1). Backscattered radiation is collected with an $\mathrm{f} / 3$-Newtonian telescope before entering a home-built polarization detector where it is $(\lambda, \pi)$-separated using dichroic mirrors and polarizing beam-splitter cubes (PBC). As shown in Fig. 1, each linear polarization channel has two PBC's to ensure an efficient partitioning between s- and ns-particle backscattering, using state-of-the-art optical components in the UV and VIS spectral ranges. To minimize any possible bias in the polarization measurement, we have quantitatively verified the specifications of each optical component at our laboratory on a dedicated test bench. Polarization cross-talks are fully negligible with $10^{-7}$ accuracy, ensuring efficient s- and ns-particle backscattering separation. Particle depolarization ratio measurements as low as $6 \times 10^{-3}$, comparable to the molecular depolarization, have been achieved for tropospheric aerosol remote sensing, which are very low values for atmospheric lidar observations (David et al., 2012). Moreover, precise laboratory alignment ensures that the same atmospheric volume is probed in the UV and the VIS spectral ranges. Finally, interference filters are used to minimize sky background contribution as well as molecular backscattering, which is strong in the UV spectral range. When exiting the photomultiplier tubes (PMT), the induced photoelectrons are sampled by a Licel TR-20 MHz, leading to $75 \mathrm{~m}$ vertical range resolution after range averaging.

\subsection{Particle depolarization ratio and backscattering coefficient vertical profiles}

To quantify the amount of ns-particles in the atmosphere, a precise polarization calibration of the detector is necessary, as detailed below. We applied the methodology proposed by Alvarez et al. (2006), which consists of applying controlled amounts of polarization cross-talks directed at studied altitudes. The detector gain electro-optics calibration constant is hence known with better than $2 \%$ uncertainty 


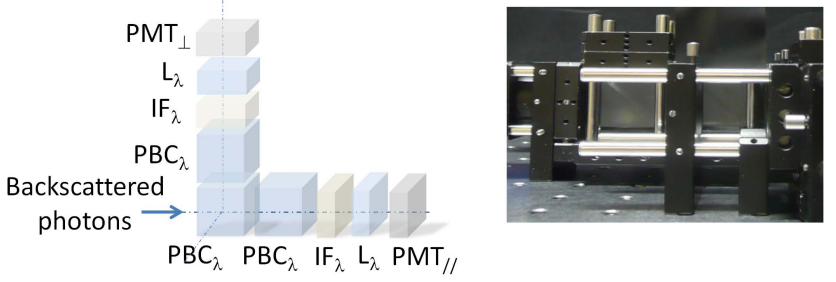

Fig. 1. Left: $3-D$ view of a Lyon $\lambda$ polarization channel: each polarization channel is composed of two polarization beamsplitter cubes (PBC), one interference filter (IF) and a collecting system (lens + photomultiplier tube PMT). Right: Photograph of the UV cross-polarized lidar polarization channel composed of two PBC. The subscripts // and $\perp$ are defined with respect to the laser incident polarization, respectively corresponding to the co- and crosspolarized polarization lidar channels.

(David et al., 2012), allowing accurate measurement of the depolarization ratio $\delta$ at wavelength $\lambda$, from the measured lidar signals. A definition of the depolarization ratio can be found in Cairo et al. (1999) or in Appendix A. Not only atmospheric particles contribute to $\delta$ but also atmospheric molecules (Cairo et al., 1999), which are efficient scatterers in the UV spectral range. Molecular anisotropy is responsible for the appearance of Raman rotational sidebands, leading to a molecular depolarization ratio $\delta_{\mathrm{m}}=3.7 \times 10^{-3}$, determined by applying optical molecular scattering theory for our interference filter bandwidth. As $\delta$ is not additive, it is linked to the (size-averaged) particle depolarization ratio $\delta_{\mathrm{p}}$ and molecular depolarization ratio $\delta_{\mathrm{m}}$ through the contrast $R_{/ /}=1+\beta_{\mathrm{p}, / /} / \beta_{\mathrm{m}, / /}$ of molecular-to-particle backscattering, called the parallel backscattering ratio, as proposed by Winker and Osborn (1992):

$\delta(\lambda)=\left(1-\frac{1}{R_{/ /}}\right) \delta_{\mathrm{p}}(\lambda)+\frac{\delta_{\mathrm{m}}}{R_{/ /}}$.

Hence, a particle-free purely molecular atmosphere corresponds to $R_{/ /}=1$. We have computed $R_{/ /}$by applying the Klett algorithm (1985) to the parallel lidar channel to correct for the particle extinction, using a lidar $S_{\mathrm{p}}$ ratio, derived from numerical simulations to be detailed in Sect. 3 (for a definition of the lidar $S_{\mathrm{p}}$ ratio, see Appendix A). In this paper, we focus on particle mixtures in the free troposphere for altitudes above $z=1.2 \mathrm{~km}$ above mean sea level. At lower altitudes, the particle load is dominated by local aerosols: a complex mixture of soot, aggregated and local pollutants is present, as discussed by Miffre et al. (2010). The Klett inversion must then account for the effects of moisture, and a more complex $S_{\mathrm{p}}$ computation is needed (David et al., 2012). The accuracy of the parallel backscattering ratio is derived from the Klett algorithm using the maximum and minimum values of $S_{\mathrm{p}}$. Then, using reanalysis model from the European Centre for Medium-range Weather Forecasts (ECMWF), we derived the $\beta_{\mathrm{m}, / /}$ vertical profile to retrieve the co-polarized particle backscattering coefficient as a function of $z$ altitude: $\beta_{\mathrm{p}, / /}(\lambda)=\left(R_{/ /}-1\right) \times \beta_{\mathrm{m}, / /}$.

The cross-polarized particle backscattering coefficient $\beta_{\mathrm{p}, \perp}(\lambda)$, which is specific to nonspherical particles, is then derived from $R_{/ /}$and $\delta$ by using Eq. (1) and the $\delta_{\mathrm{p}}$ definition $\left(\delta_{\mathrm{p}}=\beta_{\mathrm{p}, \perp} / \beta_{\mathrm{p}, / /}\right)$ :

$\beta_{\mathrm{p}, \perp}(\lambda)=\left(R_{/ /} \delta-\delta_{\mathrm{m}}\right) \times \beta_{\mathrm{m}, / /}$.

Finally, using $R_{/ /}$and $\delta$, the particle depolarization ratio $\delta_{\mathrm{p}}$ is determined from Eq. (1) as follows: $\delta_{\mathrm{p}}(\lambda)=\left(R_{/ /} \delta-\right.$ $\left.\delta_{\mathrm{m}}\right) /\left(R_{/ /}-1\right)$ and, at an altitude $z$, error bars on $\delta_{\mathrm{p}}$ are calculated by using this equation. The uncertainty in $\delta_{\mathrm{p}}$ originates from the $R_{/ /}$uncertainty, determined by the $S_{\mathrm{p}}$ uncertainty, and from the $\delta$-ratio uncertainty, derived from the measured calibrated polarization lidar signals. To reduce statistical errors, each vertical profile is an average from 4000 laser shots, corresponding to integration time of over $7 \mathrm{~min}$.

\section{Simulations of optical properties of nonspherical particles}

Numerical light-scattering simulations are exploited to separate the specific contribution of ns-particles. Certain assumptions are needed to achieve this, as detailed below. The impacts of these assumptions on the separation are considered in Sect. 5.2. To compute the optical properties (scattering matrix and cross sections) for volcanic ash and desert dust particles, we have applied the T-matrix code by Mishchenko et al. (1998), using their respective refractive index, given in Table 2. For sea salt, we have used the T-matrix algorithm by Kahnert (2013). In both of these codes, the Maxwell equations are solved analytically and exactly, with an analytical orientation averaging in order to obtain the optical properties. The model shapes they can be applied to, however, are quite limited. The optical properties are computed separately for each particle type and wavelength, from which the sizeaveraged backscattering cross sections $<(d \sigma / d \Omega)_{\mathrm{ns}}>$, depolarization ratios $\delta_{\mathrm{ns}}$ and lidar ratios $S_{\mathrm{ns}}$ are then derived.

\subsection{Particle microphysical properties}

The nonsphericity of volcanic ash, desert dust and sea-salt particles is clearly visible in the electron microscope images presented in Table 1. Volcanic ash and desert dust particles have highly irregular shapes. Sea-salt particles exhibit a cube-like shape below the $40 \%$ relative humidity crystallization point of sodium chloride (Randriamiarisoa et al., 2006). As shown by Wise et al. (2005), for relative humidity (RH) below this crystallization point, salt particles exhibit crystal faces, corresponding to effloresced particles, and the particle shapes remain unchanged as long as the $75 \%$ deliquescence point is not reached. Above the deliquescence point, salt particles become spherical solution droplets (Wise et al., 2005) 
Table 1. Electron microscope images of volcanic ash, desert dust, sea-salt (ss) and water-soluble (ws) particles (an ammonium sulfate particle is observed) taken at ILM. In this paper, ws-particles are assumed spherical (s-particles). For volcanic ash, in the absence of measurement at the ILM, the image has been provided by O. Muñoz from the Mount Spurr volcanic eruption.

\begin{tabular}{lcll}
\hline Particle type & Label & Literature references & Electron microscope image \\
\hline & & Winker and Osborn (1992) \\
Volcanic ash & Mather et al. (2003) & Muñoz et al. (2004) \\
& & Sassen et al. (2007) \\
& Schumann et al. (2011) \\
& Lindqvist et al. (2011) \\
& Eyjafjalljökull ACP SI, Hasager et al. (2012) \\
& Miffre et al. (2012a, b)
\end{tabular}

\begin{tabular}{lll}
\hline Desert dust $\quad$ (dust) & Shimizu et al. (2004) \\
& Mallet et al. (2004) \\
& Kaaden et al. (2009) \\
& Nousiainen (2009) \\
& Veselovskii et al. (2010) \\
& Ansmann et al. (2011) \\
& Nishizawa et al. (2011) \\
& Di Girolamo et al. (2012) \\
& \\
\hline Sea salt & (ss) & $\begin{array}{l}\text { Shettle et al. (1979) } \\
\\
\end{array}$ \\
& O'Dowd et al. (1997) & Murayama et al. (1999) \\
& Wise et al. (2005) \\
& Zhang (2008) \\
& Sakaï et al. (2010) \\
&
\end{tabular}

\begin{tabular}{lll}
\hline Water soluble & (ws) & O’Dowd et al. (1997) \\
& & Hess et al. (1998) \\
& Nishizawa et al. (2011) \\
& Di Girolamo et al. (2012)
\end{tabular}

Di Girolamo et al. (2012)

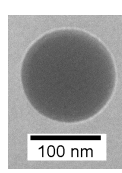

and may be treated as spherical by applying the well-known Lorentz-Mie theory. The efflorescence of ammonium nitrate particles is kinetically inhibited (Cziczo and Abbatt, 2000), while ammonium sulfate particles may effloresce (Onasch et al., 1999), as discussed in detail in Sect. 5.2. However, as published by Wise et al. (2005) and Sakai et al. (2010), ammonium sulfate crystals have a rounded shape and nearly spherical shapes. By shape, we refer to the overall shape of the particles, different from the particles' morphology, which would include internal structures and porosity effects (Nousiainen et al., 2012). The internal structure of a spherical particle, which is a source of depolarization that also affects the backscattering cross section, may be a complicating factor. Considering that point in more detail would require further numerical simulations, and such a morphological study is beyond the scope of this paper. Here we limit to RH values below the crystallization point, where the sea-salt cubic shape approximation is appropriate. Water-soluble (ws) particles are defined according to the classification of Hess et al. (1998) and include sulfate and nitrate particles as well as other organic water-soluble substances. An almost spherical ammonium sulfate particle is shown in Table 1. Due to particle hygroscopicity, these water-soluble particles tend to be spherical and will be treated as such. For each particle component, some literature references are also given in Table 1 on lidar remote sensing studies as well as numerical simulations and laboratory experiments on their light-scattering properties. When different particle types are present, they are assumed externally mixed (Mishchenko, 2009). For example, volcanic ash particles are assumed externally mixed with sulfate particles, produced by $\mathrm{SO}_{2}$ oxidation (Schumann et al., 2011). Internal mixtures, such as pollutant-coated dust or internal mixture of sulfate and organic carbon, are here not considered, because they cannot be accurately treated with the light-scattering method adopted here (see Sect. 3.2), and are thus beyond the scope of the present study. From now on, nonspherical particles (spherical) will be abbreviated as ns-particles (s-particles), the ns-subscript referring to either volcanic ash, desert dust or sea-salt particles. (There are also other types of nonspherical particles in the air such as biological nonspherical particles, but such nonspherical particles are out of the scope of this paper.

\subsection{Numerical simulations methodology}

The optical properties of volcanic ash, desert dust or seasalt particles encountered in the atmosphere are difficult to simulate with numerical models due to the strong complexity of these highly irregularly shaped ns-particles. As underlined in Nousiainen (2009) and Nousiainen et al. (2012), a completely realistic modelling should account for the nsparticles' shape and inhomogeneity, as well as birefringence. Despite the complexity, it is now well established (Dubovik, 2006; Veselovskii, 2010; Nousiainen, 2012) that the optical properties of size-shape distributions of such particles can be well mimicked by size-shape distributions of homogeneous spheroids, at least when particles are not much bigger than the wavelength. The shapes of spheroids are expressed by the so-called aspect ratio $\varepsilon=b / a$, where $a$ and $b$ are the major (minor) and minor (major) axis lengths for oblate (prolate) spheroids, respectively. The orientation and shape averaging, which smooth out the scattering matrix elements, probably plays a role in the ability of the homogeneous spheroid model to mimic optical properties encountered in the atmosphere (Nousiainen et al., 2012), For example, Nousiainen and Vermeulen (2003), Nousiainen et al. (2006), Dubovik et al. (2006) as well as Veselovskii et al. (2010) and Merikallio et al. (2011) have demonstrated that size-shape distributions of randomly oriented spheroids can reproduce the phase function of some real dust particles. Other approaches, such as the DDA method (Draine and Flatau, 1994), are also feasible and promising, but here not considered in this study.

We carried out numerical computations based on the Tmatrix method to simulate the single-scattering properties of volcanic ash, desert dust and sea-salt-like particles for different particle sizes at the wavelengths of interest. Of particular 
Table 2. Input parameters used in the numerical T-matrix simulation on ns-particles (ash, dust, sea salt): m-complex refractive index at the lidar wavelengths (UV, $\lambda_{1}=355 \mathrm{~nm}$; VIS, $\lambda_{2}=532 \mathrm{~nm}$ ), size parameter range, modelled shape, aspect ratios values and literature reference for the $m$ refractive index. The discrete set of $x$ values is $x=0.01,0.02,0.1,0.25,0.5,1$; step of 1 for $x=1$ to 10 , step of 2 for $x=10$ to 30 , 35,40 , then 45,50 . For $\varepsilon$ values, the step is 0.2 .

\begin{tabular}{llllll}
\hline Ns-particle & Label & Refractive index $m$ & Size parameter $x$ & Shape & Aspect ratio $\varepsilon$ \\
\hline Volcanic ash & (ash) & $1.54-0.0054 \mathrm{i}(\mathrm{UV}, \mathrm{VIS})$; Muñoz et al. (2004) & 0.01 to 50 & Spheroid & $1.2, \ldots, 2.6$ \\
Desert dust & (dust) & $1.57-0.007 \mathrm{i}$ (UV, VIS); Kandler et al. (2011) & 0.01 to 50 & Spheroid & $1.2, \ldots, 2.6$ \\
Sea salt & (ss) & $\begin{array}{l}1.51-0.0004 \mathrm{i}(\mathrm{UV}) \\
\end{array}$ & 0 to 20 & Cubic & $1.2, \ldots, 2.6$ \\
& & & & \\
\hline
\end{tabular}

interest were the scattering matrix $[\mathbf{F}]_{\mathrm{ns}}$ and the scattering and extinction cross sections $\mathrm{C}_{\mathrm{sca}, \mathrm{ns}}$ and $\mathrm{C}_{\mathrm{ext}, \mathrm{ns}}$, respectively, from which the lidar observables can be derived. To mimic volcanic ash and mineral dust, we used spheroids as a proxy to represent atmospheric ns-particles, assuming that oblate $(\varepsilon \geq 1)$ and prolate $(\varepsilon<1)$ spheroids are present in equal numbers (equiprobable shape distribution). Sea-salt particles were assumed to be cubes, as detailed below. However, as described in Merikallio et al. (2011) for dust particles, atmospheric samples measured in laboratory measurements (Volten et al., 2001; Muñoz et al., 2004) are more realistically mimicked by a power-law $n=3$ shape distribution. This favours extreme aspect ratio at the expense of nearly spherical spheroids, but in this way, polarization effects are better taken into account. The size parameters were chosen to be representative of atmospheric ns-particles after longrange transport. As detailed in Schumann et al. (2011), sedimentation effects may modify the ns-particles' size distribution. Moreover, in the case of a sea salt and dust particle mixture, sea-salt adhering may cause the gravitational settling of dust particles to be significantly accelerated (Zhang, 2008). Thus, for a given travel distance, a cut-off radius of a few micrometres seems reasonable according to the literature. Accordingly, we chose $x$ values varying from 0.01 to 50 after long-range transport and ran the T-matrix code for volcanic ash-like and desert dust-like particles, using the $m$ refractive indices given in Table 2, for eight $\varepsilon$ bins, varying from 1.2 up to 2.6. As described in Sect. 3.1, sea-salt particles often exhibit a cube-like shape. Hence, to compute the optical properties of sea-salt particles, we applied an extension of the T-matrix code developed by Kahnert (2013). This code, which exploits the group theory to efficiently compute different targets with discrete symmetries, is well suited to compute the optical properties of particles having discrete symmetries such as polyhedral prisms or cubes. Table 2 summarizes the input parameters used in the simulations for each particle component: ash, dust and sea-salt particles.

\subsection{Backscattering and depolarization of light by a single ns-particle}

Using T-matrix numerical code, we have computed $\mathbf{F}_{11 \text {,ns }}$, $\mathbf{F}_{22, \text { ns }}, \mathrm{C}_{\text {sca,ns }}$ and $\mathrm{C}_{\text {ext,ns }}$ as a function of the particle ra- dius $r$ for ash, dust, sea-salt and water-soluble particles at the $\lambda_{1}=355 \mathrm{~nm}$ and $\lambda_{2}=532 \mathrm{~nm}$ lidar wavelengths at the lidar backscattering angle. Using Eqs. (A3) and (A5) of Appendix A, we display in Fig. 2 the particle backscattering cross sections $(d \sigma / d \Omega)_{\mathrm{p}, / /}$ and $(d \sigma / d \Omega)_{\mathrm{p}, \perp}$ and the nsparticle depolarization ratio $\delta_{\mathrm{ns}}$ as a function of the particles radius $r$. For clarity, the backscattering cross sections are plotted per unit volume to emphasize the role of the smallest particles, as first done in Veselovskii et al. (2010). The obtained curves agree with the literature on spheroid particles (Veselovskii et al., 2010; Mishchenko et al., 2009). In particular, the backscattering cross sections are not monotonic with the particle radius $r$. Due to the homothetic scale in $r / \lambda$, wavelength-sized particles exhibit larger backscattering cross sections in the UV spectral range at $\lambda_{1}=355 \mathrm{~nm}$ than in the VIS spectral range at $\lambda_{2}=532 \mathrm{~nm}$. Hence, our sensitivity to the fine-particle mode (particles having a radius in the range of $100 \mathrm{~nm}$ ) is increased in the UV as soon as the molecular backscattering has been separately addressed, as done in Sect. 2.2. As expected, s-particles do not depolarize laser light at the lidar backscattering angle. The ns-particles' depolarization ratio reaches its maximum value around $r=0.3 \mu \mathrm{m}$ in the UV $(0.5 \mu \mathrm{m}$ in the VIS $)$. Above this maximum, the dependence of $\delta_{\text {ns }}$ with $r$ exhibits weak secondary maxima, but is otherwise almost constant when increasing the particles radius. Below $r=0.5 \mu \mathrm{m}, \delta_{\mathrm{ns}}$ rapidly increases with $r$ and depolarization ratios as high as $50 \%$ are reached so that ns-particles in the fine mode may also depolarize laser light. Such high depolarization ratios may be experimentally observed with a lidar. Even, nano-sized ns-particles depolarize laser light, as we recently demonstrated in Dupart et al. (2012). However, $\delta_{\text {ns }}$ cannot be used as a measure of particle size since it also depends on $m$ and $\varepsilon$ (Mishchenko and Hovenier, 1995).

\subsection{Backscattering and depolarization of light by an ensemble of ns-particles}

In lidar applications, the optical properties are integrated over the particle sizes and shapes. Ideally, the ns-particle size distribution (PSD) should be accurately known because this information cannot be sufficiently precisely addressed from lidar measurements. In the absence of complementary 

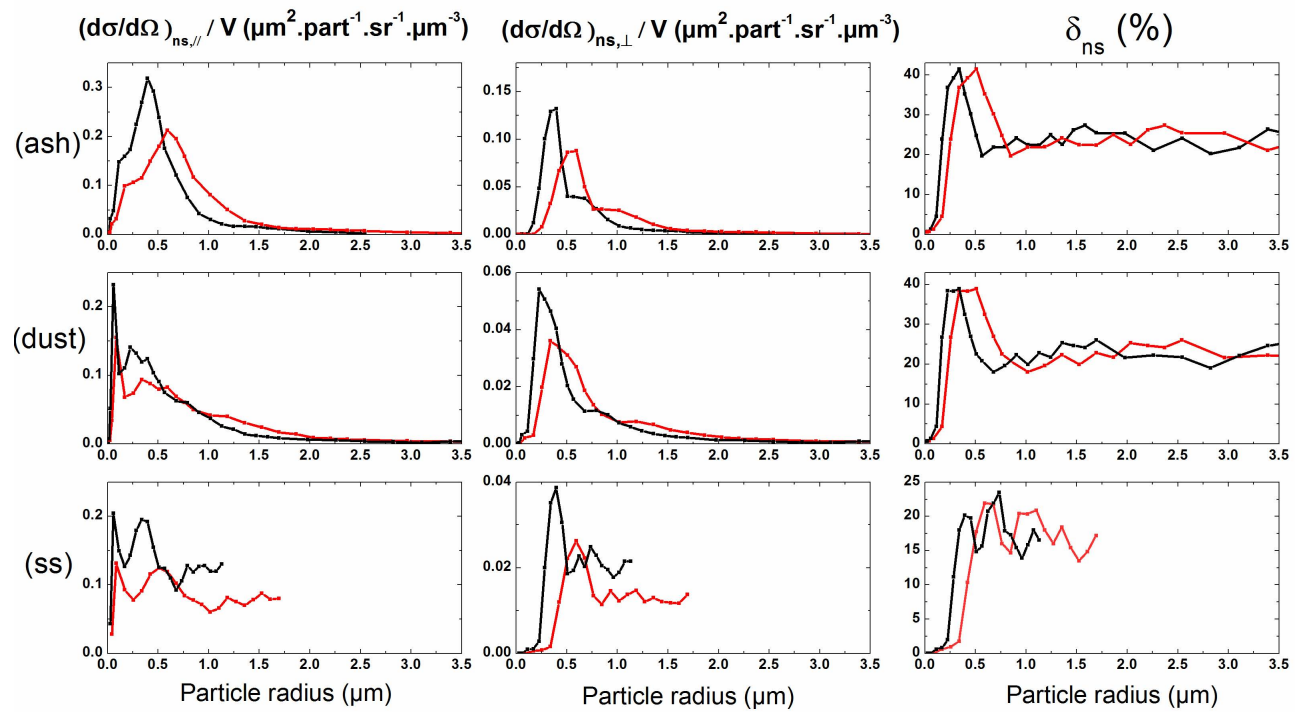

Fig. 2. Ns-particle backscattering cross section $(d \sigma / d \Omega)_{\mathrm{ns}, / /}$ and $(d \sigma / d \Omega)_{\mathrm{ns}, \perp}$ per particle volume and ns-particle depolarization ratio $\delta_{\mathrm{ns}}$ as a function of the particle radius $r$ in the UV (black, $\lambda_{1}=355 \mathrm{~nm}$ ) and in the VIS (red, $\lambda_{2}=532 \mathrm{~nm}$ ) for each ns-particle type (ash, dust and sea salt (ss)).

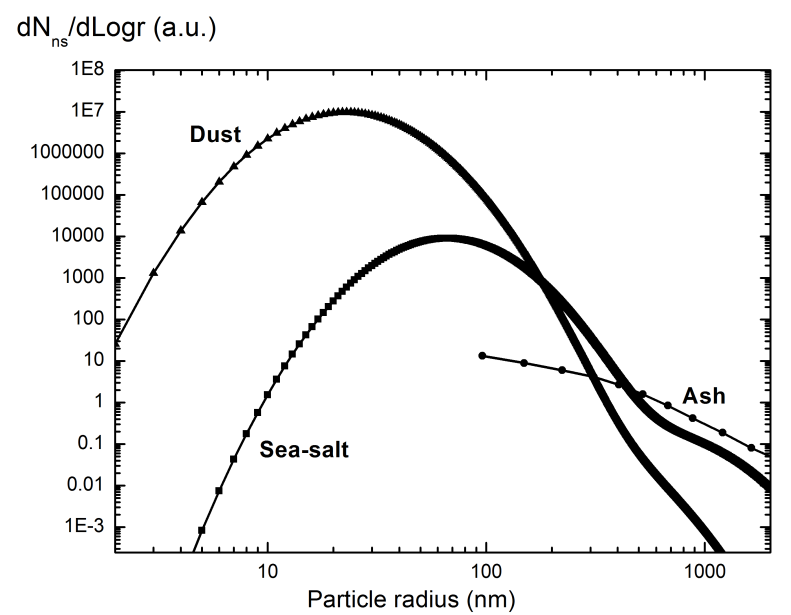

Fig. 3. Selected ns-particle size distributions (PSD) as introduced in numerical calculations for volcanic ash (Muñoz et al., 2004), desert dust (Mallet et al., 2004) and sea-salt particles (ss, O'Dowd et al., 1997).

measurements, we have used ns-PSD reported in the literature for atmospheric ns-particles after long-range transport as a proxy, with the criteria of ensuring ns-particle specificity, since our numerical simulations are built for that purpose. As an example, for volcanic ash, we used the PSD reported by Muñoz et al. (2004) in the Amsterdam light-scattering database since it is ash particle specific, while being representative of long-range transport, as discussed in detail in Miffre et al. (2012b). For dust particles, we chose the PSD of Mallet et al. (2004), who isolated the dust contribution by performing measurements after long-range transport close to
Lyon (France). We hence ensure dust particle specificity after long-range transport. To apply the methodology proposed in Sect. 4, other literature references are of course possible, provided that the given PSD is representative of longrange transport and is dust particle specific. In the terminology of Glen and Brooks (2013), we hence address the white quartz particle type, whose PSD is close to that of Mallet et al. (2004). The chosen ns-PSD for the ns-particle types considered are displayed in Fig. 3.

By integrating $(d \sigma / d \Omega)_{\mathrm{ns}, / /},(d \sigma / d \Omega)_{\mathrm{ns}, \perp}$ over the PSD, we plotted co- and cross-polarized size-averaged ns-particle cross sections $<(d \sigma / d \Omega)_{\mathrm{ns}, \perp}>$ and $<(d \sigma / d \Omega)_{\mathrm{ns}, \perp}>$ as a function of the wavelength in Fig. 4. For volcanic ash and desert dust particles, with this choice of PSD, $<(d \sigma / d \Omega)_{\mathrm{ns}, \perp}>$ is higher in the UV spectral range than in the VIS-spectral range, while the opposite behaviour is observed for sea-salt particles. The wavelength dependence of $\delta_{\mathrm{ns}}$ is also displayed. The observed dependence agrees with the literature as for desert dust (Veselovskii et al., 2010). However, the ash particle depolarization ratio $\delta_{\text {ash }}$ is different from those found in the literature (Muñoz et al., 2004; Lindqvist et al., 2011). Both approaches, however, agree within their respective error bars. The discrepancy may originate from surface roughness, which is more important for larger particles and is not accounted for in our spheroid model: indeed, in contrast to simulations based on spheroids, laboratory measurements show a tendency of increasing $\delta_{\mathrm{ns}}$ with effective radius (Nousiainen, 2009). The depolarization ratios predicted with spheroids for large volcanic ash particles may thus be underestimated. It follows that spheroids may have difficulties in predicting large particle depolarization ratios correctly. A DDA approach (Lindqvist et al., 

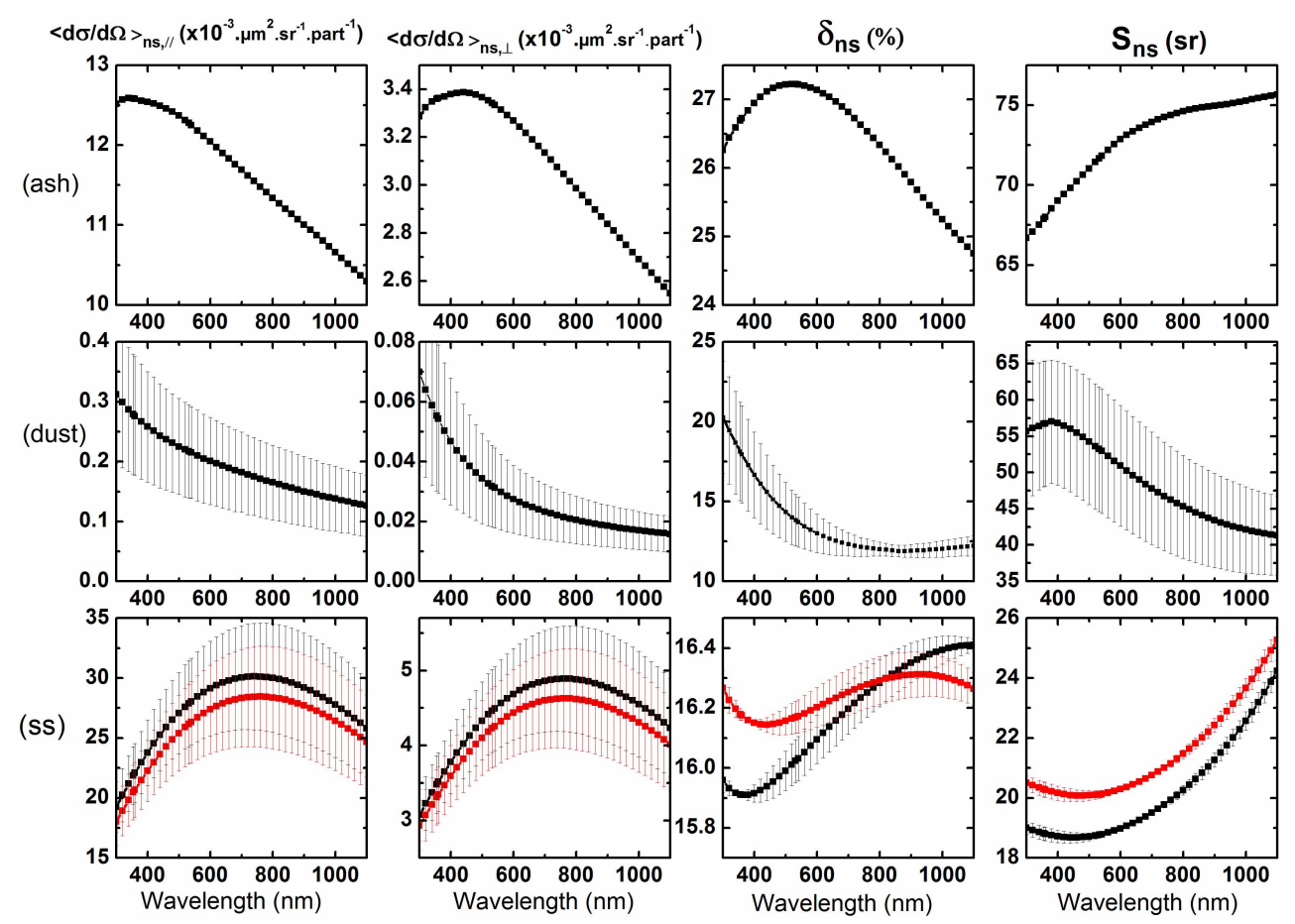

Fig. 4. Ns-particle backscattering coefficients, particle depolarization ratios $\delta_{\mathrm{ns}}$ and lidar ratios $S_{\mathrm{ns}}$ as a function of the $\lambda$ wavelength, for each ns-particles type: volcanic ash, desert dust and sea salt (ss). The plotted error bars correspond to the size and shape sensitivity study performed in Sect. 3.4. For ss-particles, two curves are represented, one for each refractive index given in Table 2.

Table 3. Results of the T-matrix simulations: depolarization ratios $\delta_{\text {ns }}$ averaged over the corresponding PSD, cross-polarized $\AA$ ngström exponents $\AA_{\mathrm{ns}, \perp}\left(\lambda_{1}=355 \mathrm{~nm}, \lambda_{2}=532 \mathrm{~nm}\right)$ and lidar ratios $S_{\mathrm{ns}}$, for each ns-particle component: volcanic ash, desert dust and sea salt (ss) at $\lambda_{1}=355 \mathrm{~nm}(\mathrm{UV})$, at $\lambda_{2}=532 \mathrm{~nm}$ (VIS).

\begin{tabular}{llllccl}
\hline Ns-particles & Label & $\delta_{\mathrm{ns}}(\mathrm{UV})[\%]$ & $\delta_{\mathrm{ns}}(\mathrm{VIS})[\%]$ & $\AA_{\mathrm{ns}, \perp}\left(\lambda_{1}=\mathrm{UV}, \lambda_{2}=\mathrm{VIS}\right)$ & $S_{\mathrm{ns}}(\mathrm{UV})[\mathrm{sr}]$ & $S_{\mathrm{ns}}(\mathrm{VIS})[\mathrm{sr}]$ \\
\hline Volcanic ash & (ash) & 26.7 & 27.2 & 0.015 & 53.6 & 56.3 \\
Desert dust & (dust) & $18.1 \pm 3.1$ & $13.8 \pm 1.6$ & $1.326 \pm 0.086$ & $56.7 \pm 8.7$ & $53.2 \pm 8.6$ \\
Sea salt & (ss) & $15.9 \pm 0.1$ & $16.2 \pm 0.1$ & $-0.478 \pm 0.034$ & $18.8 \pm 0.2$ & $20.1 \pm 0.2$ \\
\hline
\end{tabular}

2011) might be a fruitful complementary approach, but extensive DDA simulations are clearly beyond the scope of this paper. Hence, for volcanic ash, we used the laboratory measurement $\delta_{\text {ash }}=40.5 \%$ value of Muñoz et al. (2004), deduced from the Amsterdam light-scattering database, leaving more appropriate $\delta_{\text {ash }}$ numerical simulations for a forthcoming paper. Whatever the chosen $\delta_{\text {ash }}$ value, the behaviour of $\beta_{\mathrm{ns}}$ with altitude is still retraced, as shown in Sect. 4.2 (see Eq. (8) in particular) and as discussed in detail in Sect. 5.2. Finally, using the $S_{\mathrm{p}}$ definition recalled in Appendix A, we computed the lidar ratios $S_{\text {ns }}$ presented in Fig. 4 as a function of wavelength. The obtained $S_{\mathrm{ns}}$ values agree with the literature, derived from Raman lidar measurements. For example, at $\lambda_{1}=355 \mathrm{~nm}, S_{\text {ash }}$ equals $(60 \pm 5)$ sr measured by Ansmann et al. (2012), while for dust particles, Veselovskii et al. (2010) numerically computed $S_{\text {dust }}=68$ sr. Sea-salt particles exhibit $S_{\mathrm{ns}}$ values around 20 sr consistent with Ansmann et al. (2011). The Fig. 4 error bars are the results of a sensitivity study aimed at addressing the issue of size and shape variability. The size sensitivity has been tested by varying the particles radius by $\pm 10 \%$, while for the shape sensitivity, the $n=3$ shape distribution was replaced with the $n=0$ equiprobable shape distribution ( $n=1$ and $n=2$ led to similar results to the original $n=3$ shape distribution). To provide the Fig. 4 error bars that combine this size and shape sensitivity, the Table 3 numerical outputs have been computed by using the $n=0$ shape distribution and this for all particles radii. Other refinements on shape and chemical modelling are of course feasible, but would require additional computations which are beyond the scope of this paper. Note also that our sensitivity study has been performed for dust and sea-salt particles only since, as explained above, the T-matrix numerical model has difficulties in correctly simulating the depolarization of volcanic ash. For volcanic ash particles, the interested 
reader may refer to Miffre et al. (2012b), where a detailed error analysis has been performed on the chosen particles size distribution difficulties in correctly simulating the depolarization of volcanic ash.

In the literature, the spectral dependence of $<(d \sigma / d \Omega)_{\mathrm{ns}}$ $>$ is given in the form of the so-called $\dot{A}$ ngström exponent $\AA_{\text {ns }}$ which gives an indication on the particles size, as first shown by Sasano and Browell (1989). Note that the Angström exponent considered here differs from the traditional definition, which specifies the wavelength dependence of the aerosol optical depth; both definitions indicate particle size. Hence, for our set of two wavelengths $\left(\lambda_{1}, \lambda_{2}\right)$, we may introduce a cross-polarized ns-particle $\dot{A}$ ngström exponent $\AA_{\mathrm{ns}, \perp}\left(\lambda_{1}, \lambda_{2}\right)$ to be used in Sect. 4.2 presenting our new methodology:

$$
\left(\frac{\lambda_{2}}{\lambda_{1}}\right)^{-\AA_{\mathrm{ns}, \perp}}=\left\langle\left(\frac{d \sigma}{d \Omega}\right)_{\mathrm{ns}, \perp}\left(\lambda_{2}\right)\right\rangle /\left\langle\left(\frac{d \sigma}{d \Omega}\right)_{\mathrm{ns}, \perp}\left(\lambda_{1}\right)\right\rangle .
$$

Using this equation, we calculated the cross-polarized $\dot{A}$ ngström exponent $\stackrel{\circ}{\mathrm{ns}, \perp}_{(}\left(\lambda_{1}, \lambda_{2}\right)$ for volcanic ash, desert dust and sea-salt-like particles corresponding to the chosen ns-PSD.

\subsection{Summary of the numerical simulations on ns-particles}

Table 3 summarizes the results of our light-scattering simulations to be used in Sects. 4 and 5. For each ns-particle type considered, the depolarization ratio $\delta_{\mathrm{ns}}$ averaged over the corresponding PSD is given at the two lidar wavelengths, together with the cross-polarized $\dot{A}$ ngström exponent $\AA_{\mathrm{ns}, \perp}\left(\lambda_{1}=355 \mathrm{~nm}, \lambda_{2}=532 \mathrm{~nm}\right)$ and the lidar ratios $S_{\mathrm{ns}}$ needed for the Klett inversion. The sign of $\AA_{\mathrm{ns}, \perp}$ (UV, VIS) underlines our chosen PSD: dust (sea-salt) particle backscatter more light in the UV (VIS) spectral range than in the VIS (UV) spectral range.

\section{Methodology}

In this section, we describe our new methodology for lidar retrievals of atmospheric ns-particle backscattering in "two" or "three-component particle external mixtures". It is based on combining a $2 \lambda$ polarization lidar with numerical simulations that specifically account for each ns-particle component in the particle mixing. The different particle components should be assumed and be externally mixed, so that the lidar measurements, when separated for each particle component and combined with the single light-scattering properties corresponding to these components, provide backscattering coefficients specific to each ns-component.

\subsection{Depolarization of light by a two-component particle mixture}

After long-range transport, ns-particles, such as those presented in Table 1, experience chemical reactions, including potential humidification during advection (Overnevaidte et al., 2009; Schumann et al., 2011). At locations where intrusion episodes occur, the external particle mixtures are therefore often composed of both s- and ns-particles. We here show how to specifically address ns-particles' backscattering in such a particle mixture by using a $1 \lambda$ polarization lidar. In this subsection, to ease the reading, the $\lambda$ wavelength dependence is omitted.

Let us consider an external mixture of particles composed of both s- and ns-particles with a total depolarization ratio $\delta_{\mathrm{p}}$. The depolarization ratio of its ns-particles is denoted $\delta_{\mathrm{ns}}$. Since the $\delta_{\mathrm{p}}$ ratio is not additive, there is no reason for $\delta_{\mathrm{p}}$ to equal $\delta_{\mathrm{ns}}$. The distinction between $\delta_{\mathrm{p}}$ and $\delta_{\mathrm{ns}}$ is best understood in the frame of the scattering matrix formalism, recalled in Appendix A. Using the additive scattering matrix $\overline{\mathbf{F}}_{\mathrm{p}}=\mathrm{C}_{\mathrm{sca}, \mathrm{p}} \times \mathbf{F}_{\mathrm{p}} /(4 \pi)$, the mixture of particles has a scattering matrix $\overline{\mathbf{F}_{\mathrm{p}}}=\overline{\mathbf{F}_{\mathrm{s}}}+\overline{\mathbf{F}_{\text {ns }}}$, which is the sum of its s- and nscomponents. By developing this equation for the $\overline{\mathbf{F}_{11, \mathrm{p}}}$ and $\overline{\mathbf{F}_{22, \mathrm{p}}}$ matrix elements, noting that $\overline{\mathbf{F}_{11, \mathrm{~s}}}=\overline{\mathbf{F}_{22, \mathrm{~s}}}$, the $\delta_{\mathrm{p}}$ ratio of the particle mixture can be related to the depolarization ratio $\delta_{\text {ns }}$ of its ns-particles as follows (Miffre et al., 2011):

$\frac{1}{\delta_{\mathrm{p}}}=\frac{1}{\delta_{\mathrm{ns}}}+\frac{\mathbf{F}_{11, \mathrm{~s}}+\mathbf{F}_{22, \mathrm{~s}}}{\mathbf{F}_{11, \mathrm{~ns}}-\mathbf{F}_{22, n s}}\left(\frac{\mathrm{C}_{\mathrm{sca}, \mathrm{s}}}{\mathrm{C}_{\mathrm{sca}, \mathrm{ns}}}\right) \frac{N_{\mathrm{s}}}{N_{\mathrm{ns}}}$.

Hence, when s-particles are present, such as after long-range transport, the $\delta_{\mathrm{p}}$ ratio of a $\{\mathrm{s}, \mathrm{ns}\}$ particle mixture is lower than the depolarization ratio of its ns-particles $\left(\delta_{\mathrm{p}} \leq \delta_{\mathrm{ns}}\right)$. Accordingly, the same conclusion can be drawn in the frame of the lidar formalism by combining Eqs. (A4a) of the Appendix A with the above Eq. (5):

$\frac{1}{\delta_{\mathrm{p}}}=\frac{1}{\delta_{\mathrm{ns}}}+\frac{\beta_{s, / /}}{\beta_{\mathrm{ns}, \perp}}$.

In the literature, $\delta_{\mathrm{p}}$ is often compared to $\delta_{\mathrm{ns}}$ (Gasteiger et al., 2011 ) and the maximum value of $\delta_{\mathrm{p}}$ is sometimes used as a $\delta_{\text {ns }}$ measurement (Shimizu et al., 2004). Moreover, the difference between $\delta_{\mathrm{p}}$ and $\delta_{\mathrm{ns}}$ is not clearly stated to originate from the presence of s-particles, and the observed discrepancies between $\delta_{\mathrm{p}}$ and $\delta_{\mathrm{ns}}$ are sometimes attributed to imperfections originating from numerical simulations or/and experimental observations (Wiegner et al., 2009). Hence, identification of ns-particles from $\delta_{\mathrm{p}}$ (Groß et al., 2011) is not appropriate for long-range transport studies. Equation (5), or its lidar-equivalent Eq. (6), shows that $\delta_{\mathrm{p}}$ equals $\delta_{\text {ns }}$ only when there are no s-particles present $\left(N_{\mathrm{s}}=0\right)$. Since we focus on long-range transport situations, s-particles are expected to be present in the particle mixtures and lower $\delta_{\mathrm{p}}$ below $\delta_{\mathrm{ns}}$. As a consequence, the backscattering properties of ns-particles in $\{\mathrm{s}, \mathrm{ns}\}$ particle mixtures cannot be easily derived from the 
lidar-measured $\delta_{\mathrm{p}}$ value, because the latter is not a tracer specific to ns-particles only. A tracer for ns-particles can be derived from the lidar formalism by applying the superposition principle to particle backscattering coefficient $\beta_{\mathrm{p}}$, i.e. $\beta_{\mathrm{p}}=\beta_{\mathrm{s}}+\beta_{\mathrm{ns}}$, assuming no interaction between s- and nsparticles (i.e. no polarization cross-talks between polarization channels, as developed in Sect. 2.1). On each $\pi=\{/ /, \perp\}$ polarization axis, we get

$\beta_{\mathrm{p}, / /}=\beta_{s, / /}+\beta_{\mathrm{ns}, / /}$

$\beta_{\mathrm{p}, \perp}=\beta_{\mathrm{ns}, \perp}$.

Hence, only the cross-polarized particle backscattering coefficient $\beta_{\mathrm{p}, \perp}$ is a reliable tracer specific to ns-particles. Using Eq. (7b), the ns-particle backscattering coefficient $\beta_{\text {ns }}$ can be expressed as a function of $\delta_{\mathrm{ns}}$ :

$\beta_{\mathrm{ns}}=\beta_{\mathrm{ns}, \perp}\left(1+\frac{1}{\delta_{\mathrm{ns}}}\right)$.

For accurate determination of $\beta_{\mathrm{ns}}$, detailed $\beta_{\mathrm{ns}, \perp}$ lidar measurements are necessary together with computed values of $\delta_{\mathrm{ns}}$. To emphasize the contribution of s-particles to the $\delta_{\mathrm{p}}$ ratio, Eqs. (5) or (6) can be rewritten by introducing the fraction $\mathrm{X}_{\mathrm{ns}}=\beta_{\mathrm{ns}} / \beta_{\mathrm{p}}$ of ns-to-particle backscattering coefficients. By combining Eqs. (7) and (8), while noting that $\beta_{\mathrm{s}}=\beta_{s, / /}$ and $\beta_{\mathrm{s}}=\beta_{\mathrm{p}}-\beta_{\mathrm{ns}}$, we get

$$
\frac{1}{\delta_{\mathrm{p}}}=\frac{1}{\delta_{\mathrm{ns}}}+\frac{1-X_{\mathrm{ns}}}{X_{\mathrm{ns}}}\left(1+\frac{1}{\delta_{\mathrm{ns}}}\right) .
$$

Thus, the difference between $\delta_{\mathrm{p}}$ and $\delta_{\mathrm{ns}}$ can be used to determine the fraction $\mathrm{X}_{\mathrm{ns}}$ of ns-particles in the two-component particle mixture:

$X_{\mathrm{ns}}=\frac{1+\frac{1}{\delta} \mathrm{ns}}{1+\frac{1}{\delta} \mathrm{p}} \approx \delta_{\mathrm{p}}\left(1+\frac{1}{\delta_{\mathrm{ns}}}\right)$

as long as $\delta_{\mathrm{p}} \ll 1$, so that $\delta_{\mathrm{p}}$ is a tracer for $\mathrm{X}_{\mathrm{ns}}$, while $\delta_{\mathrm{ns}}$ can be determined by following the procedure detailed in Sect. 3 . Equation (10), derived from the scattering matrix, agrees with Tesche et al. (2009). Since $\delta_{\mathrm{p}}$ is sometimes assumed to equal $\delta_{\text {ns }}$, we plotted in Fig. 5 the systematic bias between $\delta_{\mathrm{p}}$ and $\delta_{\mathrm{ns}}$ as a function of $\mathrm{X}_{\mathrm{ns}}$ for each ns-component (volcanic ash, desert dust, sea-salt particles). The relative error is larger when $\delta_{\text {ns }}$ is larger, but the three curves look almost independent of $\delta_{\text {ns. }}$. For a given $\mathrm{X}_{\mathrm{ns}}$ value, the larger $\delta_{\mathrm{ns}}$ is, the larger the bias between $\delta_{\mathrm{p}}$ and $\delta_{\mathrm{ns}}$ is. Moreover, to lower the $X_{n s}$ uncertainty, the lower $\delta_{\mathrm{ns}}$ is, the more accurate the determination of $\delta_{\mathrm{p}}$ must be.

When the particle mixture $(p)=\{s, n s\}$ enters the low troposphere, it often mixes with local aerosols such as ammonium sulfate, nitrate or carbonaceous soot aggregates present

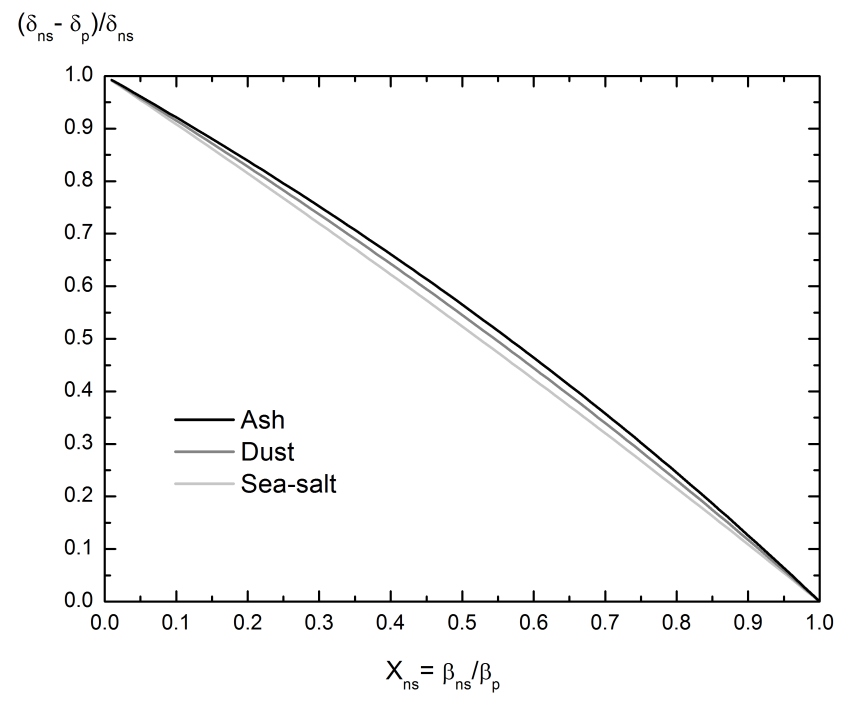

Fig. 5. Systematic bias on $\delta_{\mathrm{ns}}$ when assuming $\delta_{\mathrm{p}}$ equals to $\delta_{\mathrm{ns}}$ for $\delta_{\mathrm{ns}}=10 \%$ as for sea-salt particles (light gray), $\delta_{\mathrm{ns}}=20 \%$, as for desert dust particles (dark gray), $\delta_{\mathrm{ns}}=30 \%$, as for volcanic ash (black). This graph allows to measure the need for distinguishing $\delta_{\mathrm{p}}$ from $\delta_{\mathrm{ns}}$.

in the urban canopy (Miffre et al., 2010). To account for possible background depolarization, the particle mixture is preferably partitioned between ns- (ash, dust, sea salt) particles on the one hand, and quasi spherical particles (i.e. particles that are neither ash nor dust nor sea-salt particles) on the other hand. In this practical case, to separately retrieve the ns- and quasi-spherical particle backscattering coefficients, we offer the following set of four equations:

$\beta_{\mathrm{p}, / /}=\beta_{\mathrm{ns}, / /}+\beta_{\text {quasi-s }, / /}$

$\beta_{\mathrm{p}, \perp}=\beta_{\mathrm{ns}, \perp}+\beta_{\mathrm{sqasi}-\mathrm{s}, \perp}$

$\delta_{\mathrm{ns}}=\beta_{\mathrm{ns}, \perp} / \beta_{\mathrm{ns}, / /}$,

$\delta_{\text {quasi-s }}=\beta_{\text {non }-\mathrm{ns}, \perp} / \beta_{\text {quasi-s }, / /}$.

Four backscattering coefficients are hence to be determined, namely $\beta_{\mathrm{p}, \pi}$ with $(\mathrm{p})=\{\mathrm{ns}$, non-ns $\}$ and $\pi=\{/ /, \perp\}$. This is feasible by combining $\beta_{\mathrm{p}, / /}$ and $\beta_{\mathrm{p}, \perp}$ lidar measurements with computed $\delta_{\text {ns }}$ values, while $\delta_{\text {quasi-s }}$ can be assumed to be equal to $1 \%$ (Sakai et al., 2010). An application of this methodology is given in Sect. 5.1 (case study 1), where the mixing of volcanic ash with spherical sulfate particles is studied to retrieve vertical profiles of $\beta_{\mathrm{ash}}, \beta_{\text {sulf }}$ and $\mathrm{X}_{\mathrm{ash}}=$ $\beta_{\mathrm{ash}} / \beta_{\mathrm{p}}$. 


\subsection{Depolarization of light by a three-component particle mixture}

The mixing of ns-particles with s-particles that occurs after long-range transport may concern two different ns-particles. To retrieve such three-component mixtures, we extend the treatment introduced in Sect. 4.1 by one additional lidar wavelength.

In the three-component mixture, we label particles by numerical indices; that is, $(p)=\{n s 1, n s 2, n 12\}$, where ns1 and ns2 refer to the two ns-particle populations (see Table 1), while n12-particles belong to neither ns1- nor ns2particles. After long-range transport, the n12-population is composed of s-particles or water-soluble particles, and local aerosols such as sulfate or nitrate particles may also contribute to $\mathrm{n} 12$. In this paper, n12-particles are assumed spherical, so that water-soluble particles are simply regarded as s-particles. For an external mixture of ns1-, ns2and n12-particles, following the same methodology as in Sect. 4.1, n12-particles contribute to the $\delta_{\mathrm{p}}$ ratio of the threecomponent mixture and $\delta_{\mathrm{p}}$ is below $\max \left(\delta_{\mathrm{ns} 1}, \delta_{\mathrm{ns} 2}\right)$, where $\delta_{\mathrm{ns} 1}\left(\delta_{\mathrm{ns} 2}\right)$ is the ns1-particles' depolarization ratio (ns2). To determine the backscattering coefficients of ns-particles in the three-component mixture $(p)=\{n s 1, n s 2, n 12\}$, six unknown quantities have to be determined, corresponding to the three components (ns1, ns2, n12) assigned to the two detector polarization axes $\pi=\{/ /, \perp\}$. When dealing with a $2 \lambda$ polarization lidar experiment $(2 \beta+2 \delta$ lidar configuration), each of these backscattering coefficients has to be determined at the two lidar wavelengths $\lambda=\left\{\lambda_{1}, \lambda_{2}\right\}$. Hence, twelve unknown backscattering coefficients have to be determined, hereafter noted $\beta_{\mathrm{p}, \pi}(\lambda)$.

As shown in Sect. 2, our $2 \lambda$ polarization lidar experiments provide vertical profiles of co- and cross-polarized particle backscattering coefficient $\beta_{\mathrm{p}, / /(\lambda)}$ and $\beta_{\mathrm{p}, \perp}(\lambda)$ at wavelength $\lambda$. By applying the superposition principle to the threecomponent mixture, for the $(\lambda, \pi)$ spectral and polarization property, the $\beta_{\mathrm{p}, / /}(\lambda)$ and $\beta_{\mathrm{p}, \perp}(\lambda)$ coefficients provide a set of four equations:

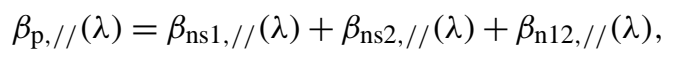

$\beta_{\mathrm{p}, \perp}(\lambda)=\beta_{\mathrm{ns} 1, \perp}(\lambda)+\beta_{\mathrm{ns} 2, \perp}(\lambda)+\beta_{\mathrm{n} 12, \perp}(\lambda)$.

For the sake of clarity, we note that Eq. (12a, c) refer to $\lambda_{1}$ wavelength, while Eq. (12b, d) refer to wavelength $\lambda_{2}$. Six more equations are then provided by numerical simulations by computing the ns-particle depolarization ratio at the two lidar wavelengths $\lambda=\left\{\lambda_{1}, \lambda_{2}\right\}$ :

$$
\begin{aligned}
& \delta_{\mathrm{ns} 1}(\lambda)=\beta_{\mathrm{ns} 1, \perp}(\lambda) / \beta_{\mathrm{ns} 1, / /}(\lambda), \\
& \delta_{\mathrm{ns} 2}(\lambda)=\beta_{\mathrm{ns} 2, \perp}(\lambda) / \beta_{\mathrm{ns} 2, / /}(\lambda),
\end{aligned}
$$

$\delta_{\mathrm{n} 12}(\lambda)=\beta_{\mathrm{n} 12, \perp}(\lambda) / \beta_{\mathrm{n} 12, / /(\lambda)}$.

The last two equations are obtained by addressing the spectral behaviour of the backscattering coefficient $\beta_{\mathrm{ns}}$. By using Eq. (A4a) of Appendix A, we may write

$\frac{\beta_{\mathrm{ns} 1, \perp}\left(\lambda_{2}\right)}{\beta_{\mathrm{ns} 1, \perp}\left(\lambda_{1}\right)}=\left\langle\left(\frac{d \sigma}{d \Omega}\right)_{\mathrm{ns} 1, \perp}\left(\lambda_{1}\right)\right\rangle$,

$\frac{\beta_{\mathrm{ns} 2, \perp}\left(\lambda_{2}\right)}{\beta_{\mathrm{ns} 2, \perp}\left(\lambda_{1}\right)}=\left\langle\left(\frac{d \sigma}{d \Omega}\right)_{\mathrm{ns} 2, \perp}\left(\lambda_{1}\right)\right\rangle$,

where the average is performed over the ns-particle size distribution (PSD). Using Eq. (4), we may express the ratio of cross-polarized backscattering cross sections in terms of the corresponding cross-polarized ns-particle $\dot{A}$ ngström exponents $\AA_{\mathrm{ns}, \perp}\left(\lambda_{1}, \lambda_{2}\right)$ introduced in Sect. 3. Note that Eqs. (12k) and (12l) hold provided that, in the lidar experiment, the same atmospheric volume is probed at both wavelengths, as done in Sect. 2. Hence, when dealing with a $2 \lambda$ polarization lidar experiment, the twelve unknown backscattering coefficients $\beta_{\mathrm{p}, \pi}(\lambda)$ can be determined from the system of twelve equations (12). As a conclusion, vertical profiles of $\beta_{\mathrm{p}, \pi}(\lambda)$ can be retrieved for each particle component $(\mathrm{p})=\{\mathrm{ns} 1, \mathrm{~ns} 2, \mathrm{n} 12\}$ at wavelength $\lambda_{1}$ and $\lambda_{2}$ :

$\beta_{\mathrm{ns} 1}(\lambda)=\beta_{\mathrm{ns} 1, / /}(\lambda)+\beta_{\mathrm{ns} 1, \perp}(\lambda)$,

$\beta_{\mathrm{ns} 2}(\lambda)=\beta_{\mathrm{ns} 2, / /}(\lambda)+\beta_{\mathrm{ns} 2, \perp}(\lambda)$

$\beta_{\mathrm{n} 12}(\lambda)=\beta_{\mathrm{n} 12, / /}(\lambda)+\beta_{\mathrm{n} 12, \perp}(\lambda)$.

$(13 e, f)$

Hence, four lidar-retrieved backscattering coefficients $\left[\beta_{\mathrm{p}, / /}(\lambda), \beta_{\mathrm{p}, \perp}(\lambda)\right.$ with $\left.\lambda=\left\{\lambda_{1}, \lambda_{2}\right\}\right]$, addressed in Sect. 2, are used in combination with eight numerically retrieved quantities $\left[\delta_{\mathrm{ns} 1}(\lambda), \delta_{\mathrm{ns} 2}(\lambda), \delta_{\mathrm{n} 12}(\lambda), \AA_{\mathrm{ns} 1, \perp}\left(\lambda_{1}, \lambda_{2}\right), \AA_{\mathrm{ns} 2, \perp}\right.$ $\left.\left(\lambda_{1}, \lambda_{2}\right)\right]$, addressed in Sect. 3, to determine the twelve nsparticle backscattering coefficients $\beta_{\mathrm{p}, \pi}(\lambda)$, with $(\mathrm{p})=\{\mathrm{ns} 1$, ns2, n12 $\}$ and $\pi=\{/ /, \perp\}$. Thus, the complete set of outputs proposed in Table 3 for ns-particles (depolarization ratio, cross-polarized $\dot{A}$ ngström exponents and lidar ratios for the Klett algorithm) is used.

\section{Application to volcanic ash, desert dust and sea-salt particle mixing}

In this section, the composition of the particles' external mixture is analysed experimentally after long-range transport through $2 \lambda$-polarization-resolved backscattering measurements performed at Lyon, France. Taking advantage of the sensitivity and accuracy achieved in the UV-VIS polarization lidar experiment and the numerical simulations carried out, the backscattering coefficients specific to volcanic ash, desert dust and sea-salt particles are retrieved by applying the methodology developed in Sect. 4 in two studied cases: 
- Case 1 is an example of depolarization of light by a two-component particle mixture after long-range transport. During the 2010 Eyjafjallajökull volcanic eruption, large quantities of volcanic ash was injected into the troposphere, leading to a safety-related 6-day airport closure. After more than $2500 \mathrm{~km}$ of transport by advection, the volcanic ash particles entering Lyon's atmosphere might have mixed with spherical particles, most likely to be hydrated sulfates, produced by $\mathrm{SO}_{2}$ oxidation (Mather et al., 2003), giving rise to a twocomponent external mixture.

- Case 2 is an example of depolarization of light by a three-component particle mixture after long-range transport. On 18 October 2011, a Saharan dust outbreak occurred at Lyon, with particles entering the Lyon troposphere after several thousand kilometres of transport by advection above the Atlantic Ocean, during which they mixed with sea-salt particles and in the troposphere over Lyon with local aerosols. This \{desert dust, seasalt, water-soluble\} particle mixture is an example of a three-component external mixture.

\subsection{Case study 1: mixing of Eyjafjallajökull volcanic ash with sulfate particles}

As shown by FLEXPART ash particle numerical dispersion model and 7-day air mass back trajectories (see Fig. 6), volcanic ash particles released from the Eyjafjallajökull volcano passed above Lyon on 19 April 2010 around 19:00 UTC above $3 \mathrm{~km}$ altitude above mean sea level. Using the methodology introduced in Sect. 4.2, we display in Fig. 7 vertical profiles of atmospheric particle UV backscattering coefficients $\beta_{\mathrm{p}, / /}, \beta_{\mathrm{p}, \perp}$ and particle depolarization ratio $\delta_{\mathrm{p}}$ on 19 April 2010 at 19:00 UTC, using $S=54 \pm 5 \mathrm{sr}$ for the Klett algorithm, in agreement with Table 3 and Ansmann et al. (2012). As a consequence of Eq. (7a, b), the co- and cross-polarized backscattering coefficients plotted in Fig. 7 are different. The presence of s-particles lowers the observed $\delta_{\mathrm{p}}$ values, which are always below $\delta_{\text {ash }}$ within our error bars. It follows that, contrary to what is generally presented in the literature, the maximum observed $\delta_{\mathrm{p}}$ value cannot be taken as a proxy for $\delta_{\text {ns }}$.

Contrary to the $\delta_{\mathrm{p}}$ profile, only ash particles contribute to the $\beta_{\mathrm{p}, \perp}$ vertical profile, as discussed in Sect. 4.1. Thus, the vertical dispersion of the volcanic ash cloud in the low troposphere of Lyon can be retraced by the $\beta_{\mathrm{p}, \perp \text { vertical pro- }}$ file: within our error bars, the achieved sensitivity allows distinguishing several successive volcanic ash layers at about $1.5,2.5,3.5$ and $4.7 \mathrm{~km}$ altitudes. This result is best seen on the observed $\beta_{\text {ash }}$ vertical profile, using Eq. (11) with $\delta_{\text {ash }}=40.5 \%$ (Muñoz et al., 2004) and $\delta_{\text {non-ash }}=1 \%$ (Sakaï et al., 2010). As shown by the comparison of the $\beta_{\mathrm{p}, \perp}$ and $\delta_{\mathrm{p}}$ vertical profiles, depolarization does not necessarily correlate with the backscattered power. The observed $3.5 \mathrm{~km}$ altitude difference between the $\beta_{\mathrm{p}, \perp}$ and the $\delta_{\mathrm{p}}$ maxima is due to the presence of spherical sulfate particles, produced by $\mathrm{SO}_{2}$ oxidation after long-range transport. The similarity between the $\mathrm{X}_{\text {ash }}$ profile and the $\delta_{\mathrm{p}}$ profile shows that $\delta_{\mathrm{p}}$ can be considered in our case as a tracer for $\mathrm{X}_{\text {ash }}$ in agreement with Eq. (10). In the literature, $\delta_{\mathrm{p}}$ is sometimes considered as a tracer for ash particles, which is true when backscattering is strongly dominated by ash, close to the source region (Gasteiger et al., 2011). Here, our long-range transport situation implies that s-particles are present in significant numbers, so that $\beta_{\mathrm{p}, \perp}$ is a tracer for the volcanic ash particles. From the ash and sulfate backscattering coefficients, number and mass concentrations can be retrieved, and the values obtained (Miffre et al., 2012a, b) agree with those measured by Schumann et al. (2011). Use of the PSD of Schumann et al. (2011) instead of that from Muñoz et al. (2004) led to only $3 \%$ lower ash number concentration, which shows the robustness of our methodology. In addition, case study 1 of a two-component particle mixture can be applied to dust and spherical particles, as published in Miffre et al. (2011).

\subsection{Case study 2: mixing of desert dust, sea-salt and water-soluble particles}

This second case study is related to the possible mixing of desert dust particles with sea-salt and water-soluble particles after long-range transport. Such a particle mixture occurred at Lyon for example on 18 October 2011 due to favourable meteorological conditions after more than $2500 \mathrm{~km}$ advection from the dust source region. As a stand-alone lidar experiment provides no chemical analysis, 7-day air mass back trajectories have been used to identify the possible origin of the air masses at our remote site. As shown in Fig. 8, in the morning of 18 October 2011, the air masses passing above the lidar station about $1.5 \mathrm{~km}$ altitude ( $a$ layer) were originating from a sea-salt source region and around $3 \mathrm{~km}$ ( $b$ layer) from a desert dust source region. In the evening, the $b$ and $a$ layers were inverted, with air masses originating from a dust source region in the $a$ layer (from a sea-salt region in the $b$ layer). Hence, a possible mixing of sea-salt and desert dust particles occurred during daytime in the low troposphere. The $a$ and $b$ layers are delimited by temperature inversion layers that can be seen in the vertical profiles of potential temperature, also present in Fig. 8, showing that the troposphere was stably stratified. Over our 260-290 K temperature range, the efflorescence relative humidity of ammonium sulfate particles is temperature independent and equal to $32 \%$ (Onasch et al., 1999). In agreement with Sect. 3.1, the cubic shape model is applicable for sea-salt particles for altitudes above $2 \mathrm{~km}$ since ammonium sulfate particles, when they effloresce, exhibit a rounded shape (Wise et al., 2005; Sakaï et al., 2010). Thus, at these altitudes, the cubic shape model was applicable for sea-salt particles, in agreement with Sect. 3.1. Note that the presence of sea-salt particles is possible at such altitudes, as demonstrated by Ikegami et al. (1994). 

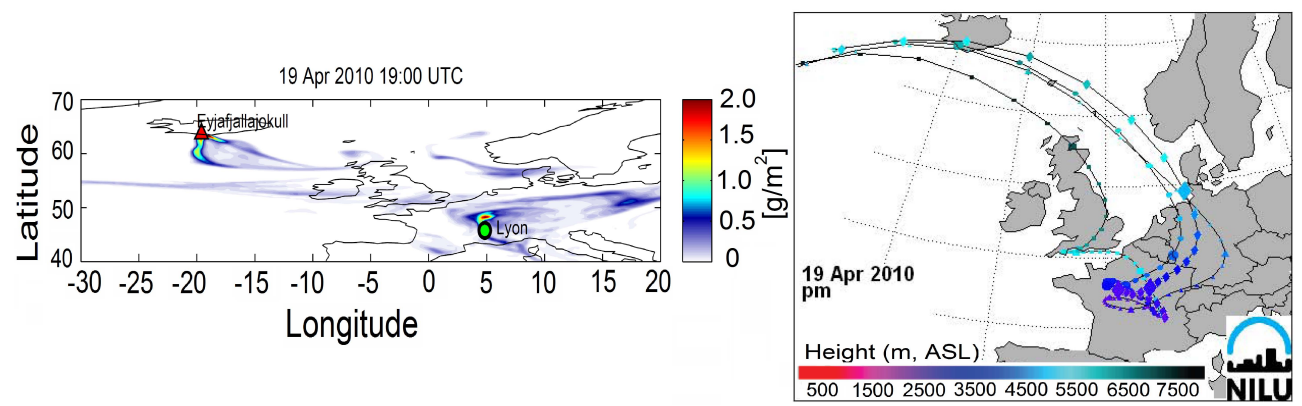

Fig. 6. Evidence of the presence of volcanic ash over Lyon on 19 April at 19:00 UTC. Left: NILU FLEXPART ash particle numerical dispersion model for 19 April 2010 at 19:00 UTC. Right: NILU FLEXTRA 7-day air mass back trajectories on 19 April at 18:00 UTC (2 km, triangles; $3 \mathrm{~km}$, circles; $5 \mathrm{~km}$ altitude, squares) and at 12:00 UTC (3 km, diamonds).

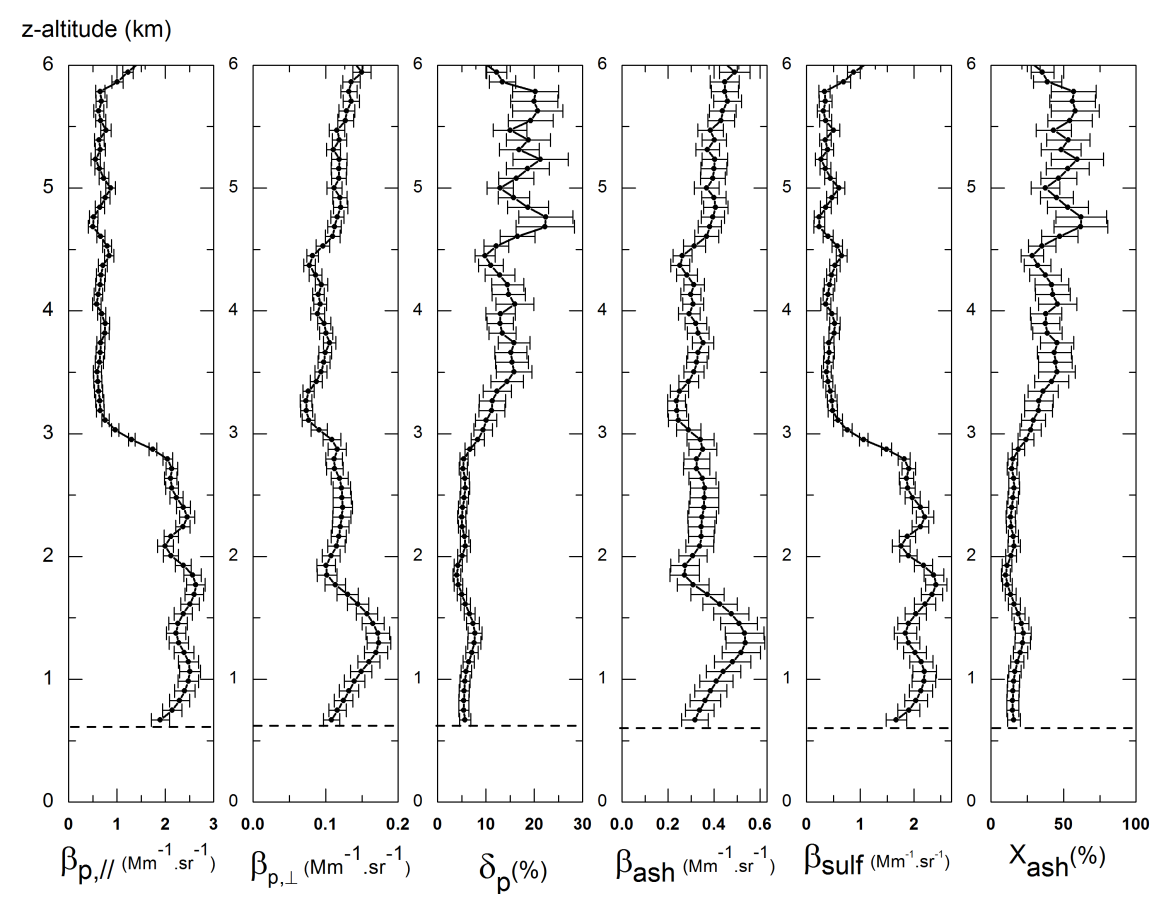

Fig. 7. Vertical profiles of backscattering coefficients $\beta_{\mathrm{p}, / /}, \beta_{\mathrm{p}, \perp}$, depolarization ratio $\delta_{\mathrm{p}}$, retrieved $\beta_{\text {ash }}$ and $\beta_{\text {sulf }}$ coefficients and ash particle backscattering fraction $\mathrm{X}_{\mathrm{ash}}=\beta_{\mathrm{ash}} / \beta_{\mathrm{p}}$ in the mixed \{ash, sulfate\} particle cloud on 19 April 2010 at 19:00 UTC at Lyon. The experiment is performed in the UV $(\lambda=355 \mathrm{~nm})$.

Using the Sect. 4.2 methodology, we derived timealtitude maps of co- and cross-polarized backscattering coefficients and particle depolarization ratio $\delta_{\mathrm{p}}$ as displayed in Fig. 9. To correct for the particle extinction, we chose $\mathrm{S}(\mathrm{UV})=50 \pm 5 \mathrm{sr}$ and $\mathrm{S}(\mathrm{VIS})=60 \pm 5 \mathrm{sr}$, in agreement with the literature (Murayama et al., 1999). These values are between the computed values for dust and sea salt to be seen in Table 3. Each time-altitude map has adjusted colour scales to emphasize the temporal behaviour of two main atmospheric layers having different thicknesses, located around the $a$ and the $b$ layers. This layering is clearly visible in the UV and VIS cross-polarized backscattering time-altitude maps, which are ns-particle specific, as shown by Eq. (7b). The par- ticle depolarization ratio maps exhibit maximum $\delta_{\mathrm{p}}$ values equal to $11 \%$ at $\lambda_{1}=355 \mathrm{~nm}$ and $9 \%$ at $\lambda_{2}=532 \mathrm{~nm}$, well below the $\delta_{\mathrm{ns}}$ values computed for sea-salt or dust particles (see Table 3 ), due to the presence of spherical water-soluble particles. We have run our $2 \beta+2 \delta$ algorithm to solve the set of 12 equations (12) and separately retrieve the backscattering coefficients of desert dust, sea-salt (ss) and water-soluble (ws) particles as a function of altitude. Figure 10 displays the retrieved vertical profiles of $\beta_{\text {dust }}, \beta_{\mathrm{ss}}$ and $\beta_{\mathrm{ws}}$, together with the corresponding $\beta_{\mathrm{p}, / /}, \beta_{\mathrm{p}, \perp}$ and $\delta_{\mathrm{p}}$ vertical profiles and the fraction of each component (dust, ss, ws) in the mixed particles plume on 18 October at 16:15 UTC. At that time, as shown in Fig. 8, for altitudes above $2 \mathrm{~km}$, the Lyon 

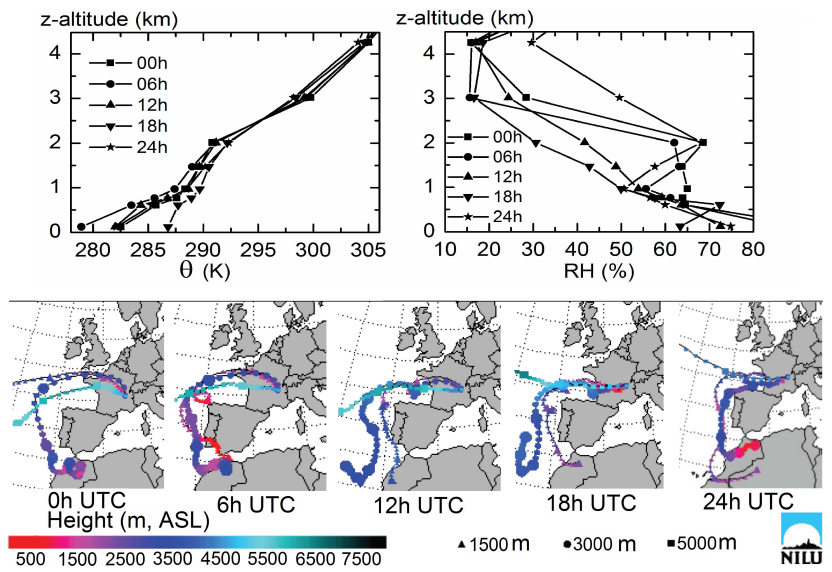

Fig. 8. Upper panel: relative humidity $(\mathrm{RH})$ and potential temperature $(\theta)$ vertical profiles on 18 October 2011 at Lyon (Météo France). Lower panel: FLEXTRA 7-day air mass back trajectories showing the history of air masses arriving in the Lyon atmosphere on 18 October 2011.

troposphere is stable, as depicted by the potential temperature, while the relative humidity is below the $40 \% \mathrm{RH}$ seasalt crystallization point, allowing sea-salt particles to depolarize. The nonsphericity of both dust and sea-salt particles must hence be taken into account.

This methodology is complex, but it is a necessity for particle mixture observations after long-range transport where the approximation $\delta_{\mathrm{p}}=\delta_{\mathrm{ns}}$ no longer holds. Because of its novelty, it is yet to be validated in the atmosphere by independent co-located measurements. Such a validation work is now under progress. We here discuss the possible influence of computed numerical values of $\delta_{\mathrm{ns}}$ and $\AA_{\mathrm{ns}, \perp}$ (UV, VIS) for dust and ss-particles (see Table 3 for the used numerical values) on the retrieval results. To test the robustness of our new methodology, we used somewhat arbitrary test values for $\delta_{\mathrm{ss}}$ and $\AA_{\mathrm{ns}, \perp}$ (UV, VIS). As shown by Eq. (8), the effect of a different $\delta_{\text {ns }}$ value is to shift the corresponding $\beta_{\mathrm{ns}}$ profile. Therefore, the behaviour of $\beta_{\mathrm{ns}}$ with altitude is still retraced for all $\delta_{\text {ns }}$ values considered. Quantitatively, when using $\delta_{\mathrm{ss}}=33 \%$ instead of $10 \%, \beta_{\mathrm{ss}}$ decreases by a factor of almost 3 (11/4 exactly), which in turn may increase the observed $\beta_{\mathrm{ws}}$ value, depending on the corresponding $\beta_{\text {dust }}$ value observed. Note that that an assumption of $\delta_{\mathrm{ss}}=0$ results in a singularity in Eq. (8). Consequently, very close to $\delta_{\mathrm{ss}}=0$, we noticed that the retrieved $\beta_{\mathrm{ss}}$ and $\beta_{\mathrm{ws}}$ values were very different from those observed in Fig. 10, underlining the importance of taking into account the ss-particle nonsphericity when RH values allow ss-particles to be nonspherical. The computed cross-polarized Ȧngström exponent $\AA_{\mathrm{ns}, \perp}$ (UV, VIS) may also be questioned. In agreement with Sect. 3, Fig. 10 shows that dust particles contribute more to particle backscattering at the UV spectral range than in the VIS, while sea-salt particle backscattering is stronger in the VIS spectral range. The $\AA_{\text {dust, } \perp}$ (UV, VIS) and $\AA_{\text {ss }, \perp}$
(UV, VIS) values can be considered as convergence criteria in our algorithm since, for very different values of $\AA_{\text {dust, } \perp} \perp$ (UV, VIS) and $\AA_{\mathrm{ss}, \perp}$ (UV, VIS), negative particle backscattering coefficients were retrieved. Hence, to obtain accurate retrievals of dust, sea-salt and ws-particle backscattering coefficients, care should be taken on the choice of PSD when applying our new methodology. To be quantitative, we have run our $2 \beta+2 \delta$ algorithm by including the Table 3 error bars on the cross-polarized $\dot{A}$ ngström exponent and the UV-VIS ns-particle depolarization ratios. The corresponding errors on the retrieved particle backscattering coefficients are quite low, which shows the robustness of our new methodology. For dust particles, the model variability induces a $4 \%$ uncertainty on the retrieved cross-polarized backscattering coefficient (20\% on the parallel coefficient). Salt particles exhibit an error bar in the range of $10 \%$ for both polarization axes. These error bars are almost independent of the laser wavelength. Moreover, by using UV-VIS laser light, we have increased our sensitivity to particles in the fine-particle mode. Hence, precise polarization measurement allows minimizing the contribution of possible frozen hydrometeors which may be present in the troposphere.

Figure 10 shows vertical profiles of dust, sea-salt and wsparticles revealing a complex vertical layering of the Lyon troposphere. In contrast to what is observed in the twocomponent methodology, due to the presence of ws-particles, the $\beta_{\text {dust }}$ vertical profile is not complementary of the $\beta_{\text {ss }}$ vertical profile. We here analyse the obtained vertical profiles in the $a$ and the $b$ layers. Up to $3.0 \mathrm{~km}$ altitude, where a temperature inversion is observed, in the $a$ layer, dust (sea-salt) particles contribute to nearly $40 \%(10 \%)$ to the total particle backscattering coefficient. The vertical profile of wsparticles is much more complicated to describe, except when $\mathrm{X}_{\mathrm{ss}}$ is constant, such as between 2.7 and $3.0 \mathrm{~km}$ altitude, in which case $X_{\text {dust }}$ and $X_{w s}$ are in opposite phases with respect to altitude. Despite its complex behaviour, the $\beta_{\mathrm{ws}}$ vertical profile closely follows the $\beta_{\mathrm{p}, / /}$ vertical profile, into which $\mathrm{s}$-particles mainly contribute. Above $3.0 \mathrm{~km}$ altitude, in the $b$ layer, the fractions of dust, ss and ws-particles in the total particle backscattering vary with altitude, revealing a very complex vertical layering. A very interesting point is to be seen around the extrema observed at a $3.5 \mathrm{~km}$ altitude where, in the $\mathrm{UV}$, the $\beta_{\text {dust }}$ and the $\beta_{\mathrm{ss}}$ vertical profiles are in opposite phases with respect to altitude. As recently shown in Dupart et al. (2012), this behaviour can be related to new particle formation events. This observation clearly indicates that the proposed methodology is able to reveal very complex particle microphysical behaviour.

\section{Conclusions and outlook}

In this paper, we have proposed and applied a new methodology to evaluate the partitioning of two- or three-component particle external mixtures of volcanic ash, desert dust, sea- 

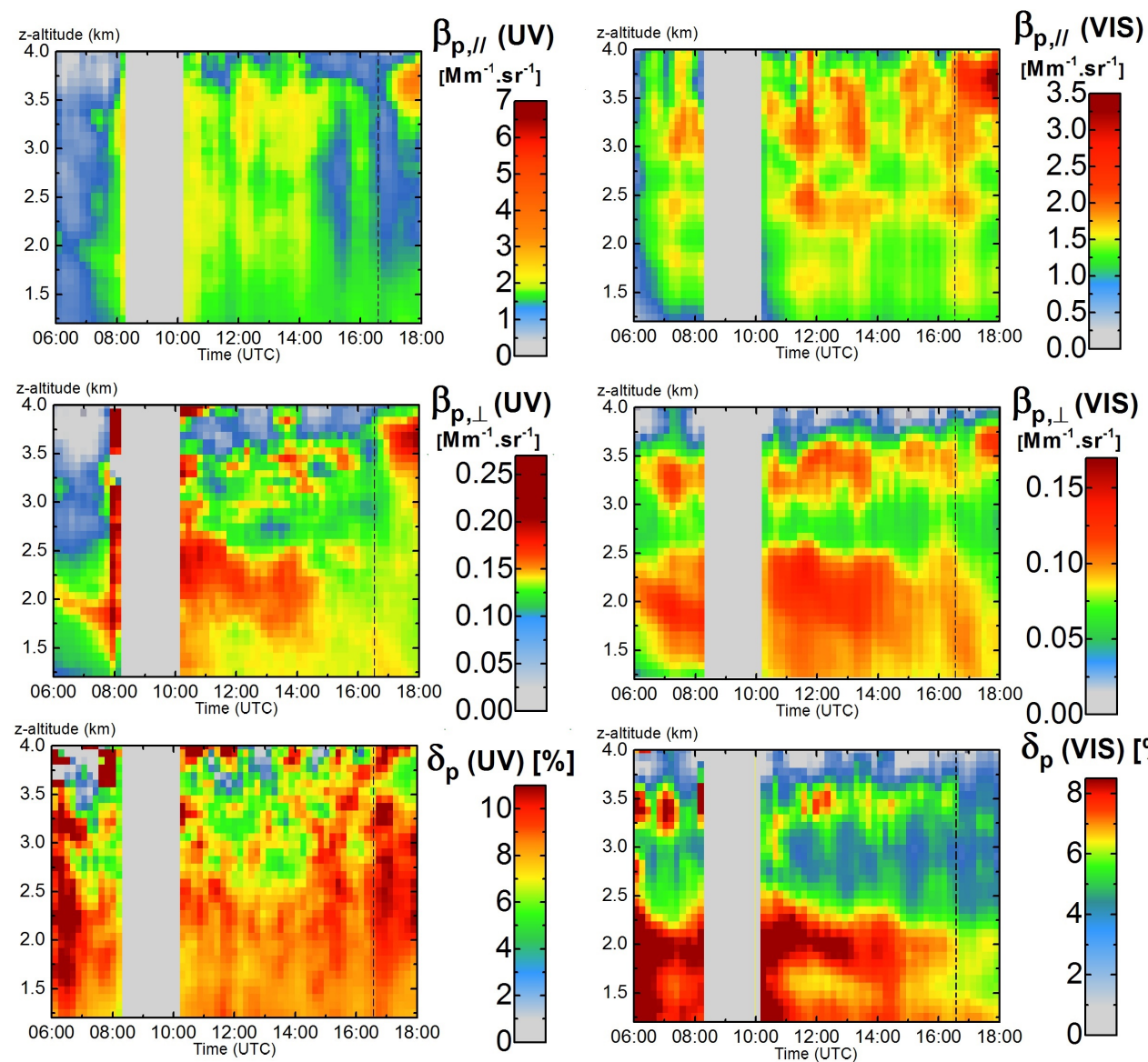

$\delta_{p}(\mathrm{VIS})[\%]$

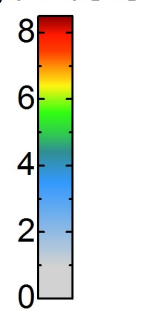

Fig. 9. Time-altitude maps of $\beta_{\mathrm{p}, / /}, \beta_{\mathrm{p}, \perp}$ and $\delta_{\mathrm{p}}$ in the UV $\left(\lambda_{1}=355 \mathrm{~nm}\right.$, left three panels) and in the VIS ( $\lambda_{2}=532 \mathrm{~nm}$, right three panels)

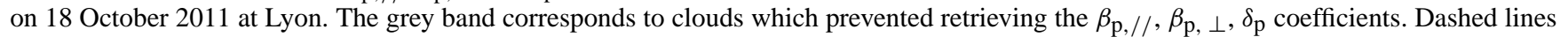
correspond to Fig. 10, case study at 16:15 UTC.

salt and water-soluble particles. Such a partitioning is particularly interesting after long-range transport, where the mixing of these particles is often observed. Our new methodology uses both spectral $(\lambda)$ and polarization $(\pi)$ properties of the light backscattered by atmospheric ns-particles. It consists in combining dual-wavelength polarization lidar measurements with light-scattering numerical simulations and air mass back trajectories. The $2 \lambda$ polarization lidar experiment (Sect. 2) is used to efficiently partition the particle mixture into its nonspherical components, while the singlescattering numerical simulations (Sect. 3) are used to compute the backscattering and depolarization properties of each nonspherical component (volcanic ash, desert dust and seasalt particles). The originality of this work precisely consists in combining instruments (polarization lidar measurements and light-scattering numerical simulations), which are often used separately in the literature, where the measured depolarization $\delta_{\mathrm{p}}$ of the particle mixture is often compared to the computed depolarization $\delta_{\mathrm{ns}}$ of its ns-particles. We have shown in Sect. 4 that, after long-range transport, $\delta_{\mathrm{p}}$ differs from $\delta_{\mathrm{ns}}$, as a consequence of the presence of s- particles, which contribute to $\delta_{\mathrm{p}}$. Therefore, care should be taken when using the maximum value of $\delta_{\mathrm{p}}$ as a proxy for $\delta_{\mathrm{ns}}$. We hence identified a tracer for nonspherical particles in two/three-component particle mixtures. By combining sensitive and accurate UV-VIS polarization lidar experiment with light-scattering simulations, we have shown in Sect. 4 how to retrieve range-resolved vertical profiles of ns-particle backscattering coefficients specific to each particle component present in the two/three-component particle mixture (development of a $2 \beta+2 \delta$ algorithm). Moreover, in Sect. 5, we discussed the inherent assumptions and demonstrated the performance of this new methodology in two case studies: mixing of volcanic ash with sulfate particles ("two-component particle mixture"), external mixing of desert dust with sea-salt and water-soluble particles ("threecomponent particle mixture"). To our knowledge, for the first time, a three-component external mixture has hence been partitioned into its ns-particles components by taking into account the nonsphericity of each ns-particles component (i.e., both sea-salt and desert dust particle nonsphericity). The assumption of sea-salt particle nonsphericity appeared prudent 


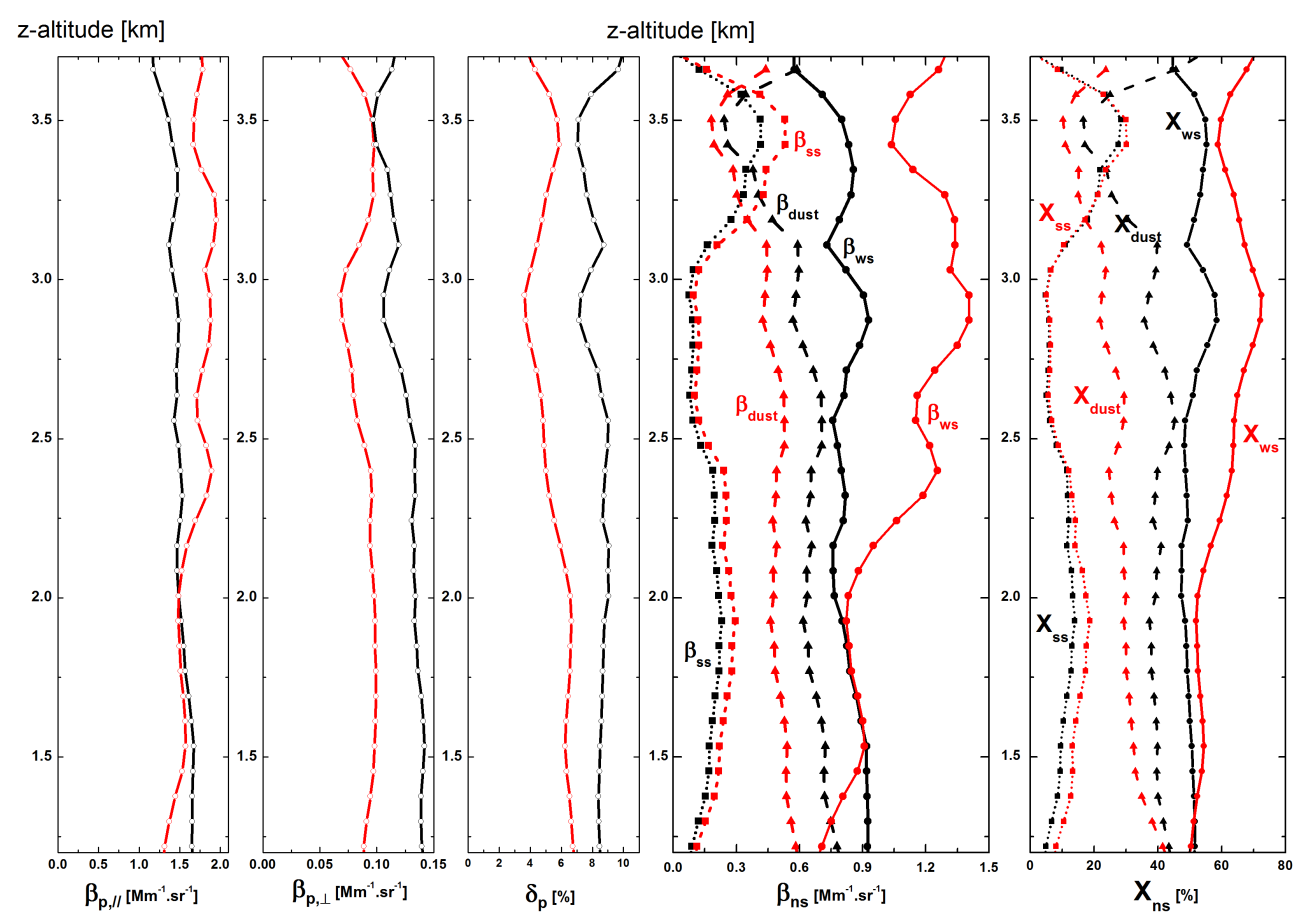

Fig. 10. Vertical profiles of $\beta_{\mathrm{p}, / /}, \beta_{\mathrm{p}, \perp}, \delta_{\mathrm{p}}, \beta_{\mathrm{dust}}$ (triangles), $\beta_{\mathrm{ss}}$ (squares) and $\beta_{\mathrm{ws}}$ (spheres) and fraction of ns-particles (dust, ss) and ws-particles (ws, spherical) in the three-component mixture on 18 October 2011 at 16:15 UTC at Lyon (France), addressed in the UV $\left(\lambda_{1}=355 \mathrm{~nm}\right.$, black $)$ at and in the VIS $\left(\lambda_{2}=532 \mathrm{~nm}\right.$, red $)$. To ease the reading, error bars are not plotted on this graph.

after carefully looking at the RH vertical profiles during the analysed Saharan dust outbreak. The achieved sensitivity and accuracy on our UV-VIS polarization lidar experiment allowed revealing the complex vertical layering of the Lyon troposphere by exhibiting the separate contributions of dust, sea-salt and water-soluble particles in the particle mixture. The robustness of the proposed methodology has also been studied by running the $2 \beta+2 \delta$ algorithm with out-of-range values for the dust and sea-salt particle depolarization ratio. It should be noted that, to apply our new methodology, care should be taken with the ns-particle size distribution assumed in the numerical computations, which must be ns-particle specific and representative of these ns-particles after longrange transport. Moreover, our retrieval lidar methodology $(2 \beta+2 \delta$ algorithm) is very general in the sense that it can be applied by using parameter values that could be derived by other means than the here-used T-matrix numerical simulations. A further validation of this methodology is clearly needed and will be published in a following paper. Moreover, our new methodology could be further improved. To quote only a few possible steps, for the numerical simulations, an extension to some more complex and realistic shapes using DDA approximation (Nousiainen et al., 2012) or/and including porosity effects (Lindqvist et al., 2012) would be desirable. For the polarization lidar experiment, as underlined by Nicolet et al. (2012), use of circular depolarization might also provide new insights. To conclude, we showed that the com- bined use of UV-VIS polarization lidar remote sensing experiments with numerical simulations on ns-particles and air mass back trajectories makes possible a range-resolved and robust analysis of atmospheric aerosols with particle mixtures of up to three components.

\section{Appendix A}

\section{Theoretical considerations on light scattering by atmospheric particles}

In this appendix, we present the polarization lidar observables suitable for range-resolved experimental observations of ns-particles in the atmosphere in terms of the scattering matrix formalism.

\section{A1 Scattering matrix formalism}

Scattering of light by an ensemble of particles of arbitrary size, shape and chemical composition can be described by the scattering matrix formalism, which relates the Stokes vectors $[\boldsymbol{I}, \boldsymbol{Q}, \boldsymbol{U}, \boldsymbol{V}]^{T}$ of the incident (inc) and scattered (sca) light waves with respect to the laser-scattering plane through the non-additive F-phase matrix (M. I. Mishchenko et al., 2002):

$$
\left(\begin{array}{c}
\boldsymbol{I}_{\text {sca }} \\
\boldsymbol{Q}_{\text {sca }} \\
\boldsymbol{U}_{\text {sca }} \\
\boldsymbol{V}_{\text {sca }}
\end{array}\right)=\frac{C_{\text {sca, }}}{4 \pi d^{2}}\left[\begin{array}{llll}
\mathbf{F}_{11, \mathrm{p}} & \mathbf{F}_{12, \mathrm{p}} & \mathbf{F}_{13, \mathrm{p}} & \mathbf{F}_{14, \mathrm{p}} \\
\mathbf{F}_{21, \mathrm{p}} & \mathbf{F}_{22, \mathrm{p}} & \mathbf{F}_{23, \mathrm{p}} & \mathbf{F}_{24, \mathrm{p}} \\
\mathbf{F}_{31, \mathrm{p}} & \mathbf{F}_{32, \mathrm{p}} & \mathbf{F}_{33, \mathrm{p}} & \mathbf{F}_{34, \mathrm{p}} \\
\mathbf{F}_{41, \mathrm{p}} & \mathbf{F}_{42, \mathrm{p}} & \mathbf{F}_{43, \mathrm{p}} & \mathbf{F}_{44, \mathrm{p}}
\end{array}\right]\left(\begin{array}{c}
\boldsymbol{I}_{\text {inc }} \\
\boldsymbol{Q}_{\text {inc }} \\
\boldsymbol{U}_{\text {inc }} \\
\boldsymbol{V}_{\text {inc }}
\end{array}\right),
$$


where the subscript $\mathrm{p}$ refers to the particle, $d$ is the distance between the particle and the observer and $C_{\text {sca,p }}$ is the scattering cross section of the particle $\mathrm{p}$, which depends on the wavelength $\lambda$ of the radiation and on the particle radius $r$. For an ns-particle, $r$ is defined here as the volume equivalent radius, i.e. the radius of an s-particle with the same volume as the considered ns-particle. For numerical simulations (see Sect. 3), it is useful to introduce the size parameter $x=2 \pi r / \lambda$, which is dimensionless. The $\mathbf{F}_{i j}$-matrix elements and the scattering cross sections are functions of the particles' size, shape and chemical composition, and depend on the scattering angle, on the size parameter $x$ and on the complex refractive index $m$, through which absorption may occur. The F matrix and the T matrix used in Sect. 3 are, in a way, related as both relate properties of incident and scattered waves, but they are quite different in practice because the F matrix relates the waves described by the Stokes parameters, whereas the T matrix relates waves expressed as spherical function expansions. In this paper, the T matrix is just used internally in our new methodology (see Sect. 3.2) and we only consider the quantities in the lidar backscattering direction. Moreover, particles are assumed to be randomly oriented (see Nicolet et al., 2012 for a study of depolarization of light by horizontally oriented ice crystals). Following Mishchenko et al. (1995b), the backscattering matrix is diagonal and depends only on $\mathbf{F}_{11, \mathrm{p}}$ and $\mathbf{F}_{22, \mathrm{p}}$. At distances that are large compared to the particles' size, and for a perfectly linearly polarized incident light, i.e. as for polarization lidar experiments, the backscattered light wave is then given by

$$
\begin{aligned}
& \left(\begin{array}{c}
\boldsymbol{I}_{\mathrm{sca}, / /}+\boldsymbol{I}_{\mathrm{sca}, \perp} \\
\boldsymbol{I}_{\mathrm{sca}, / /}-\boldsymbol{I}_{\mathrm{sca}, \perp} \\
0 \\
0
\end{array}\right) \\
& =\frac{\mathrm{C}_{\mathrm{sca}, \mathrm{p}}}{4 \pi d^{2}}\left[\begin{array}{cccc}
\mathbf{F}_{11, \mathrm{p}} & 0 & 0 & 0 \\
0 & \mathbf{F}_{22, \mathrm{p}} & 0 & 0 \\
0 & 0 & -\mathbf{F}_{22, \mathrm{p}} & 0 \\
0 & 0 & 0 & \mathbf{F}_{11, \mathrm{p}}-2 \mathbf{F}_{22, \mathrm{p}}
\end{array}\right]\left(\begin{array}{l}
1 \\
1 \\
0 \\
0
\end{array}\right)
\end{aligned}
$$

, where $\pi=\{/ /, \perp\}$ polarization components are, respectively, called the co- and cross-polarized polarization components with respect to the incident laser linear polarization.

\section{A2 Polarization lidar formalism}

In the polarization lidar formalism, the backscattered intensities $\boldsymbol{I}_{\text {sca, } / /}$ and $\boldsymbol{I}_{\text {sca }, \perp}$ are measured separately with a polarization-sensitive detector. These intensities can be used to define co- and cross-polarized particle backscattering cross sections, which depend on $r, m$ and $\lambda$ :

$$
\begin{aligned}
& \left(\frac{d \sigma}{d \Omega}\right)_{\mathrm{p}, / /}(r, m, \lambda)=d^{2} \frac{\boldsymbol{I}_{\mathrm{sca}, / /}}{\boldsymbol{I}_{\mathrm{inc}}}=\frac{\mathrm{C}_{\mathrm{sca}, \mathrm{p}}}{4 \pi}\left(\frac{\mathbf{F}_{11, \mathrm{p}}+\mathbf{F}_{22, \mathrm{p}}}{2}\right) \\
& \left(\frac{d \sigma}{d \Omega}\right)_{\mathrm{p}, \perp}(r, m, \lambda)=d^{2} \frac{\boldsymbol{I}_{\mathrm{sca}, \perp}}{\boldsymbol{I}_{\mathrm{inc}}}=\frac{C_{\mathrm{sca}, \mathrm{p}}}{4 \pi}\left(\frac{\mathbf{F}_{11, \mathrm{p}}-\mathbf{F}_{22, \mathrm{p}}}{2}\right)
\end{aligned}
$$

by using Eq. (A2). Usually, a lidar measures size-averaged particle backscattering cross sections, which define the so-called volume particle backscattering coefficients (in $\left.\mathrm{Mm}^{-1} \mathrm{sr}^{-1}\right)$ :

$$
\beta_{\mathrm{p}, \pi}(\lambda)=\int_{\mathrm{PSD}}\left(\frac{d \sigma}{d \Omega}\right)_{\mathrm{p}, \pi} n_{\mathrm{p}}(r) d r=N_{\mathrm{p}} \times\left\langle\left(\frac{d \sigma}{d \Omega}\right)\right\rangle_{\mathrm{p} \pi},
$$

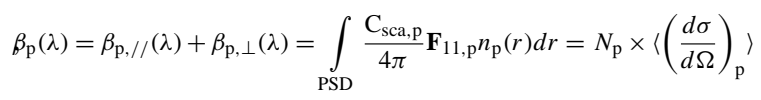

where the integration is performed over the particle size distribution (PSD) defined by the particle number density $n_{\mathrm{p}}(r)=d N_{\mathrm{p}} / d r$ for a particle number concentration $N_{\mathrm{p}}$ (in part $\mathrm{m}^{-3}$ ). In contrast to ns-particles, s-particles, for which

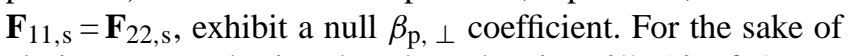
clarity, we emphasize that the subscripts $\{/ /, \perp\}$ of $\beta_{\mathrm{p}}$ are relative to the polarization detector and defined with respect to the incident linear polarization and do not apply to atmospheric parameters (Gimmestad, 2008). The volume particle backscattering coefficient is additive and depends on the size, shape, $\lambda$ and $m$ of the particles in the volume. Backscattering thus occurs from both the s- and ns-particles. Contrary to backscattering, extinction is not sensitive to polarization effects for randomly oriented particles. Here, the extinction will be characterized by the particles' lidar ratio $S_{\mathrm{p}}=\alpha_{\mathrm{p}}$ $(\lambda) / \beta_{\mathrm{p}}(\lambda)$, where $\alpha_{\mathrm{p}}(\lambda)$ is the integral of the extinction coefficient of the particle $\mathrm{C}_{\mathrm{ext}, \mathrm{p}}$ over the PSD. Moreover, the relative amount of power $\boldsymbol{I}_{\mathrm{sca}, \perp} / \boldsymbol{I}_{\mathrm{sca}, / /}$ in the co- and crosspolarized polarization components is an often-used quantity in the lidar community, known as the particles' linear depolarization ratio $\delta_{\mathrm{p}}$. By combining Eqs. (A1) and (A2), for a particle with a radius $r, \delta_{\mathrm{p}}$ is defined as follows (Cairo et al., 1999):

$\delta_{\mathrm{p}}(r, \lambda)=\frac{\boldsymbol{I}_{\mathrm{sca}, \perp}}{\boldsymbol{I}_{\mathrm{sca}, / /}}=\frac{\boldsymbol{I}_{\mathrm{sca}}-\boldsymbol{Q}_{\mathrm{sca}}}{\boldsymbol{I}_{\mathrm{sca}}+\boldsymbol{Q}_{\mathrm{sca}}}=\frac{\mathbf{F}_{11, \mathrm{p}}-\mathbf{F}_{22, \mathrm{p}}}{\mathbf{F}_{11, \mathrm{p}}+\mathbf{F}_{22, p}}$.

Like $\mathbf{F}_{11, \mathrm{p}}$ and $\mathbf{F}_{22, \mathrm{p}}$, the $\delta_{\mathrm{p}}$ ratio depends on the shape, $r, m$ and $\lambda$, and is non-additive. Equation (A5) shows that s-particles do not depolarize laser light, contrary to nsparticles, for which the polarization state of the incident light is modified. This non-zero linear polarization change is called depolarization (Harris-Hobbs and Cooper, 1987; Baumgardner et al., 2012). These shape-dependent features arise in polarization-resolved backscattering from the interference of different parts of an anisotropic particle, although absorption may somewhat dampen this interference. $\mathrm{Nu}-$ merical simulations show that the magnitude of $\delta_{\mathrm{p}}$ is not a clear indicator of the particles' overall shape or morphology (Nousiainen et al., 2012). However, as also demonstrated in this paper, it is a clear indicator for deviation from particle isotropy, and can be used to partition a mixture of particles into its s- and ns-components, provided that sensitive and accurate polarization lidar measurements are performed (see 
Sect. 2). In polarization lidar experiments, the particles' depolarization ratio is integrated over the PSD, and hereafter noted $\delta_{\mathrm{p}}(\lambda)$. By using Eq. (A4a), $\delta_{\mathrm{p}}$ is equal to the ratio $\beta_{\mathrm{p}, \perp}$ $/ \beta_{\mathrm{p}, / /}$, as is well known in the lidar community.

Acknowledgements. The authors thank M. Kahnert and M. I. Mishchenko for making their T-matrix codes available, O. Muñoz for proving the volcanic ash electron microscope image, A. M. Fjaeraa and A. Stohl from NILU for providing FLEXTRA air mass back trajectories and FLEXPART ash numerical dispersion at Lyon, the Lyon Centre Technologique des Microstructures for the use of the electron microscope and Région Rhône-Alpes for financial support. In part, this study has been funded by the Academy of Finland (contract 125180).

Edited by: D. Baumgardner

\section{References}

Alvarez, J. M., Vaughan, M. A., Hostelier, C. A., Hunt, W. H., and Winker, D. M.: Calibration technique for polarization-sensitive Lidars, J. Atm. Ocean. Tech., 23, 683-699, 2006.

Ansmann, A., Petzold, A., Kandler, K., Tegen, I., Wendisch, M., Muller, D., Weinzierl, B., Muller, T., and Heintzenberg, J.: Saharan Mineral Dust Experiments SAMUM-1 and SAMUM-2: what have we learned?, Tellus, 63B, 403-429, 2011.

Ansmann, A., Seifert, P., Tesche, M., and Wandinger, U.: Profiling of fine and coarse particle mass: case studies of Saharan dust and Eyjafjallajökull/Grimsvötn volcanic plumes, Atmos. Chem. Phys., 12, 9399-9415, doi:10.5194/acp-12-9399-2012, 2012.

Baumgardner, D., Newton, R., and Boyouk, N.: The Aerosol Particle Spectrometer with Polarization Detection (APSPD) Part I: laboratory studies, Atmos. Chem. Phys. Discuss., in preparation, 2012.

Bourcier, L., Sellegri, K., Chaussse, P., Pichon, J. M., and Laj, P.: Seasonal variation of water-soluble inorganic components in aerosol size-segregated at the puy de Dome station (1465 m a.s.1.), France, J. Atm. Chem., 69, 47-66, 2011.

Boyouk, N., Léon, F. F., Delbarre, H., Podvin, T., and Deroo, C., Impact of the mixing boundary layer on the relationship between $\mathrm{PM}_{2.5}$ and aerosol optical thickness, Atmos. Environ. 44, 271277, 2010.

Cairo, F., Di Donfrancesco, G., Adriani, A., Pulvirenti, L., and Fierli, F.: Comparison of various depolarization parameters measured by lidar, Appl. Optics, 38, 4425-4432, 1999.

Córdoba-Jabonero, C., Guerrero-Rascado, J. L., Toledo, D., Parrondo, M., Yela, M., Gil, M., and Ochoa, H. A.: Depolarization ratio of polar stratospheric clouds in coastal Antarctica: comparison analysis between ground-based Micro Pulse Lidar and spaceborne CALIOP observations, Atmos. Meas. Tech., 6, 703-717, doi:10.5194/amt-6-703-2013, 2013.

Cziczo, D. J. and Abbatt, J. P.: Infrared Observations of the Response of $\mathrm{NaCl}, \mathrm{MgCl}_{2}, \mathrm{NH}_{4} \mathrm{HSO}_{4}$, and $\mathrm{NH}_{4} \mathrm{NO}_{3}$ Aerosols to Changes in Relative Humidity from 298 to 238 K, J. Phys. Chem. A, 104, 2038-2047, 2000.

David, G., Miffre, A., Thomas, B., and Rairoux, P.: Sensitive and accurate dual-wavelength UV-VIS polarization detector for opti- cal remote sensing of tropospheric aerosols, Appl. Phys. B, 108, 197-216, 2012.

Di Girolamo, P., Summa, D., Bhawar, R., Di Iorio, T., Cacciani, M., Veselovskii, I., Dubovik, O., and Kolgotin A.: Raman lidar observations of a Saharan dust outbreak event: characterization of the dust optical properties and determination of particle size and microphysical parameters, Atmos. Environ. 50, 66-78, 2012.

Draine, B. T. and Flatau, P. J.: Discrete-dipole approximation for scattering calculations, J. Opt. Soc. Am., 11, 1491-1499, 1994.

Dubovik, O., Sinyuk, A., Lapyonok, T., Holben, B. N., Mishchenko, M., Yang, P., Eck, T. F., Volten H., Muñoz, O., Veihelmann, B., van der Zande, W. J., Leon, J.-F., Sorokin, M. and Slutsker, I.: Application of spheroid models to account for aerosol particle nonsphericity in remote sensing of desert dust, J. Geophys. Res., 111, D11208, doi:10.1029/2005JD006619, 2006.

Dupart Y., King, S. M., Nekat, B., Nowak, A., Wiedensohler, A., Herrmann, H., David, G., Thomas, B., Miffre, A., Rairoux P., D’Anna B., and George, C.: Mineral dust photochemistry induces nucleation events in the presence of SO2, Proc. Natl. Acad. Sci. USA, 109, 20842-7, doi:10.1073/pnas.1212297109, 2012.

Freudenthaler, V., Esselborn, M., Wiegner, M., Heese, B., Tesche, M., Ansmann, A., Müller, D., Althausen, D., Wirth, M., Fix, A., Ehret, G., Knippertz, P., Toledano, C., Gasteiger, J., Garhammer, M. and Seefeldner ,M.: Depolarization ratio profiling at several wavelengths in pure Saharan dust during Samum 2006, Tellus, 61B, 165-179, 2009.

Gasteiger, J., Groß, S., Freudenthaler, V., and Wiegner, M.: Volcanic ash from Iceland over Munich: mass concentration retrieved from ground-based remote sensing measurements, Atmos. Chem. Phys., 11, 2209-2223, doi:10.5194/acp-11-22092011, 2011.

Gimmestad, G.: Reexamination of depolarization in lidar measurements, Appl. Opt., 47, 3795-3802, 2008.

Glen, A. and Brooks, S. D.: A new method for measuring optical scattering properties of atmospherically relevant dusts using the Cloud and Aerosol Spectrometer with Polarization (CASPOL), Atmos. Chem. Phys., 13, 1345-1356, doi:10.5194/acp-13-13452013, 2013.

Groß, S., Tesche, M., Freudenthaler, V., Toledano, C., Wiegner, M., Ansmann, A., Althausen, D., and Seefeldne, M.: Characterization of Saharan dust, marine aerosols and mixtures of biomassburning aerosols and dust by means of multi-wavelength depolarization and Raman lidar measurements during SAMUM 2, Tellus 63B, 706-724, 2011.

Harris-Hobbs, R. L. and Cooper, W. A.: Field evidence supporting quantitative predictions of secondary ice production rates, J. Atmos. Sci., 44, 1071-1082, doi:10.1175/1520-0469, 1987.

Hasager, C. B., Birmili, W., Pappalardo, G. and Prata F.: Atmospheric implications of the volcanic eruptions of Eyjafjallajökull, Iceland 2010, Eyjafjalljökull, Special Issue, Atmos. Chem. Phys., 2012.

Hess, M., Koepke, P., and Schult I.: Optical Properties of Aerosols and Clouds: The Software Package OPAC, 79, 831-844, 1998.

Ikegami, M., Okada, K., Zaizen, Y., and Makino, Y.: Sea-salt in the upper troposphere, Tellus 46B, 142-151, 1994.

Kaaden, N., Massling, A., Schladitz, A., Müller, T., Kandler, K., Schütz, L., Weinzierl, B., Petzold, A., Tesche, M., Leinert, S., Deutscher, C., Ebert, M., Weinbruch, S., and Wiedensohler, A.: State of mixing, shape factor, number size distribution, and 
hygroscopic growth of the Saharan anthropogenic and mineral dust aerosol at Tinfou, Morocco, Tellus 61B, 51-63, 2009.

Kandler, K., Lieke, K., Benker, N., Emmel, C., Küpper, M., MüllerEbert D., Ebert, M., Scheuvens D., Schladitz, A., Schütz, L. and Weinbruch, S.: Electron microscopy of particles collected at Praia, Cape Verde, during the Saharan Mineral Dust Experiment: particle chemistry, shape, mixing state and complex refractive index, Tellus 63B, 475-496, 2011.

Kahnert, M.: Numerical methods in electromagnetic scattering theory. J. Quant. Spec. Rad. Transf., 79-80, 775-824, 2003.

Kahnert, M.: The T-matrix code Tsym for homogeneous dielectric particles with finite symmetries, J. Quant. Spec. Rad. Transf., 123, 62-78, doi:10.1016/j.jqsrt.2012.12.019, 2013.

Klett, J.: Lidar inversion with variable backscatter/extinction ratios, Appl. Opt. 24, 1638-1643, 1985.

Lindqvist H. Nousiainen, T., Zubko, E., and Munoz, O.: Optical modeling of vesicular volcanic ash particles, J. Quant. Spec. Rad. Transf. 112, 1871-1880, 2011.

Mallet, M., Roger, J. C., Despiau, S., Putaud, J. P., and Dubovik, O.: A study of the mixing state of black carbon in urban zone, J. Geophys. Res, 109, D04202, doi:10.1029/2003JD003940, 2004.

Marenco, F. and Hogan, R. J.: Determining the contribution of volcanic ash and boundary layer aerosol in backscatter lidar returns: A three-component atmosphere approach, J. Geophys. Res., 116, doi:10.1029/2010JD015415, 2011.

Mather, T. A., Pyle, D. M., and Oppenheimer, C.: Tropospheric Volcanic Aerosol, Volcanism and the Earth's Atmosphere, Geophys. Monogr., 139, 189-212, doi:10.129/139GM12, 2003.

Merikallio, S., Lindqvist, H., Nousiainen, T., and Kahnert, M.: Modelling light scattering by mineral dust using spheroids: assessment of applicability, Atmos. Chem. Phys., 11, 5347-5363, doi:10.5194/acp-11-5347-2011, 2011.

Miffre, A., Abou Chacra, M., Geffroy, S., Rairoux, P., Soulhac, L., Perkins, R. J., and Frejafon, E.: Aerosol load study in urban area by Lidar and numerical model, Atmos. Environ., 44, 1152-1161, 2010.

Miffre, A., David, G., Thomas, B., and Rairoux, P.: Atmospheric non-spherical particles optical properties from UV-polarization lidar and scattering matrix, Geophys. Res. Lett., 38, L16804, doi:10.1029/2011GL048310, 2011.

Miffre, A., David, G., Thomas, B., Rairoux, P., Fjaeraa, A. M., Kristiansen, N. I., and Stohl, A.: Volcanic aerosol optical properties and phase partitioning behavior after long-range advection characterized by UV-Lidar measurements, Atmos. Environ. 48, 76$84,2012 \mathrm{a}$.

Miffre, A., David, G., Thomas, B., Abou Chacra, M., and Rairoux, P.: Interpretation of accurate UV-Polarization Lidar measurements: Application to volcanic ash number concentration retrieval, J. Atmos. Ocean. Technol., 29, 558-568, doi:10.1175/JTECH-D-11-00124.1, 2012b.

Mishchenko, M. I.: Electromagnetic scattering by nonspherical particles: A tutorial review, J. Quant. Spec. Rad. Transf., 110, 808832, 2009.

Mishchenko, M. I. and Hovenier, J. W.: Depolarization of light backscattered by randomly oriented non spherical particles, Opt. Lett., 20, 1356-1359, doi:10.1364/OL.20.001356, 1995.

Mishchenko, M. I. and Travis, L. D.: Capabilities and limitations of a current Fortran implementation of the T-matrix method for randomly oriented rotationally symmetric scatterers, J. Quant. Spec- trosc. Radiat. Transf., 60, 309-324, 1998.

Mishchenko, M. I., Lacis, A. A., Carlson, B. E., and Travis, L. D.: Nonsphericity of dust-like tropospheric aerosols: Implications for aerosol remote sensing and climate modeling, Geophys. Res. Lett., 22, 1077-1080, doi:10.1029/95GL00798, 1995.

Mishchenko, M. I., Wiscombe, W. J., Hovenier, J. W. and Travis, L. D.: Overview of scattering by nonspherical particles, edited by: Mishchenko, M. I., Hovenier, J. W. and Travis, L. D., Light Scattering by Nonspherical Particles, Academic Press, San Diego, CA, USA, Chap. 2, 29-60, 2000.

Mishchenko, M. I., Travis, L. D., and Lacis, A. A.: Scattering, absorption and emission of Light by small particles, 3rd edition, Cambridge University Press, UK, 2002.

Müller, D., Wandinger, U., Althausen, D., and Fiebig, M.: Comprehensive particle characterization from three-wavelength Ramanlidar observations, Appl. Opt., 40, 4863-4869, 2001.

Muñoz, O., Volten, H., Hovenier, J. W., Veihelmann, B., van der Zande, W. J., Waters, L. B. F. M., and Rose, W. I.: Scattering matrices of volcanic ash particles of Mount St Helens, Redoubt, and Mount Spurr volcanoes, J. Geophys. Res., 109, D16201, doi:10.1029/2004JD004684, 2004.

Murayama, T., Okamoto, H., Kaneyasu, N., Kamataki, H., and Miura, K.: Application of lidar depolarization measurement in the atmospheric boundary layer: Effects of dust and sea-salt particles, J. Geophys. Res., 104, 31781-31792, doi:10.1029/1999JD900503, 1999.

Nicolet, M., Schnaiter, M., and Stetzer, O.: Circular depolarization ratios of single water droplets and finite ice circular cylinders: a modeling study, Atmos. Chem. Phys., 12, 4207-4214, doi:10.5194/acp-12-4207-2012, 2012.

Nishizawa, T., Sugimotoa, N., Matsuia, I., Shimizua, A., and Okamotob, H.: Algorithms to retrieve optical properties of three component aerosols from two-wavelength backscatter and onewavelength polarization lidar measurements considering nonsphericity of dust, J. Quant. Spec. Rad. Transf., 112, 254-267, 2011.

Nousiainen, T.: Optical modeling of mineral dust particles: a review, J. Quant. Spec. Rad. Tranf., 110, 1261-1279, 2009.

Nousiainen, T. and Vermeulen, K.: Comparison of measured singlescattering matrix of feldspar particles with T-matrix simulations using spheroids, J. Quant. Spec. Rad. Transf., 79, 1031-1042, 2003.

Nousiainen, T., Kahnert, M., and Veihelmann, B.: Light scattering modeling of small feldspar aerosol particles using polyhedral prisms and spheroids, J. Quant. Spec. Rad. Transf., 101, 471487, 2006.

Nousiainen, T., Zubko, E., Lindqvist, H., Kahnert, M., and Tyynel, J.: Comparison of scattering by different nonspherical, wavelength-scale particles, J. Quant. Spec. Rad. Transf., 113, 2391-2405, 2012.

O’Dowd C., Smith, M. H., Consterdine, I. E., and Lowe, J. A.: Marine aerosol, sea salt, and the marine sulfur cycle: a short review, Atmos. Environ., 31, 73-80, 1997.

Onasch, T. B., Siefere, R. L., Brooks, S. D., Prenni, A. J., Murray, B., Wilson, M. A., and Tolbert, M. A.: Infrared spectroscopie study of the deliquescence and effiorescence of ammonium sulfate aerosol as a function of temperature, J. Geophys. Res., 104, 21317-21326, 1999. 
Ovadnevaite, J., Ceburnis, D., Plauskaite-Sukiene, K., Modini, R., Dupuy, R., Rimselyte, I., Ramonet, R., Kvietkus, K., Ristovksi, Z., Berresheim, H., and O'Dowd, C.: Volcanic sulfate and arctic dust plumes over the North Atlantic Ocean, Atmos. Environ., 43, 4968-4974, 2009.

Ramaswamy, V., Chanin, M. L., Angell, J., Barnett, J., Gaffen, D., Gelman, M., Keckhut, P., Koshelkov, Y., Labitzke, K., Lin, J.-J. R., O’Neill, A., Nash, J., Randel, W., Rood, R., Shine, K., Shiotani, M., and Swinbank, R.: Stratospheric temperature trends: observations and model simulations, Rev. Geophys., 39, 71-122, 2001.

Randriamiarisoa, H., Chazette, P., Couvert, P., Sanak, J., and Mégie, G.: Relative humidity impact on aerosol parameters in a Paris suburban area, Atmos. Chem. Phys., 6, 1389-1407, doi:10.5194/acp-6-1389-2006, 2006.

Riccobono, F., Rondo, L., Sipilä, M., Barmet, P., Curtius, J., Dommen, J., Ehn M., Ehrhart, S., Kulmala, M., Kürten, A., Mikkilä, J., Paasonen, P., Petäjä, T., Weingartner, E., and Baltensperger, U.: Contribution of sulfuric acid and oxidized organic compounds to particle formation and growth, Atmos. Chem. Phys., 12, 9427-9439, doi:10.5194/acp-12-9427-2012, 2012.

Robock, A., Volcanic eruptions and climate, Rev. Geophys., 38, 191-219, 2000.

Sakaï, T., Nagai, T., Zaizen, Y., and Mano, Y.: Backscattering linear depolarization ratio measurements of mineral, sea-salt, and ammonium sulfate particles simulated in a laboratory chamber, Appl. Opt., 49, 4441-4449, 2010.

Sasano, Y. and Browell, E. V.: Light scattering characteristic of various aerosol types derived from multiple wavelength lidar observations, Appl. Opt., 28, 1670-1679, 1989.

Sassen, K., Zhu, J., Webley, P., Dean, K., and Cobb, P.: Volcanic ash plume identification using polarization lidar: Augustine eruption, Alaska, Geophys. Rev. Lett., 34, L08803, doi:10.1029/2006GL027237, 2007.

Shimizu, A., Sugimoto, N., Matsui, I., Arao, K., Uno, I., Murayama, T., Kagawa, N., Aoki, K., Uchiyama, A., and Yamazaki, A.: Continuous observations of Asian dust and other aerosols by polarization lidars in China and Japan during ACE-Asia. J. Geophys. Res., 109, D19S17, doi:10.1029/2002JD003253, 2004.

Shettle, E. P. and Fenn, R. W.: Models for the Aerosols of the Lower Atmosphere and the Effects of Humidity Variations on Their Optical Properties, AFGL-TR-79-0214, 1979.

Schnaiter, M., Büttner, S., Möhler, O., Skrotzki, J., Vragel, M., and Wagner, R.: Influence of particle size and shape on the backscattering linear depolarisation ratio of small ice crystals - cloud chamber measurements in the context of contrail and cirrus microphysics, Atmos. Chem. Phys., 12, 10465-10484, doi:10.5194/acp-12-10465-2012, 2012.

Schumann, U., Weinzierl, B., Reitebuch, O., Schlager, H., Minikin, A., Forster, C., Baumann, R., Sailer, T., Graf, K., Mannstein, H., Voigt, C., Rahm, S., Simmet, R., Scheibe, M., Lichtenstern, M., Stock, P., Rüba, H., Schäuble, D., Tafferner, A., Rautenhaus, M., Gerz, T., Ziereis, H., Krautstrunk, M., Mallaun, C., Gayet, J.F., Lieke, K., Kandler, K., Ebert, M., Weinbruch, S., Stohl, A., Gasteiger, J., Groß, S., Freudenthaler, V., Wiegner, M., Ansmann, A., Tesche, M., Olafsson, H., and Sturm, K.: Airborne observations of the Eyjafjalla volcano ash cloud over Europe during air space closure in April and May 2010, Atmos. Chem. Phys., 11, 2245-2279, doi:10.5194/acp-11-2245-2011, 2011.
Sugimoto, N. and Lee, C. H.: Characteristics of dust aerosols inferred from lidar depolarization measurements at two wavelengths, Appl. Opt., 45, 7468-7474, doi:10.1364/AO.45.007468, 2006.

Sugimoto, N., Matsui, I., Shimizu, A., Uno, I., Asai, K., Endoh, T., and Nakajima, T.: Observation of dust and anthropogenic aerosol plumes in the Northwest Pacific with a two-wavelength polarization lidar on board the research vessel Mirai, Geophys. Res. Lett., 29, 7-1-7-4, doi:10.1029/2002GL015112, 2002.

Tesche, M., Ansmann, A., Müller, D., Althausen, D., Engelmann, R., Freudenthaler, V., and Groß, S.: Vertically resolved separation of dust and smoke over Cape Verde using multiwavelength Raman and polarization lidars during Saharan Mineral Dust Experiment 2008, J. Geophys. Res., 114, D13202, 2009.

Vernier, J.-P., Pommereau, J.-P., Thomason, L. W., Pelon, J., Garnier, A., Deshler, T., Jumelet, J., and Nielsen, J. K.: Overshooting of clean tropospheric air in the tropical lower stratosphere as seen by the CALIPSO lidar, Atmos. Chem. Phys., 11, 96839696, doi:10.5194/acp-11-9683-2011, 2011.

Veselovskii, I., Dubovik, O., Kolgotin, A., Lapyonok, T., Di Girolamo, P., Summa, D., Whiteman, D. N., Mishchenko, M., and Tanré, D.: Application of randomly oriented spheroids for retrieval of dust particle parameters from multiwavelength lidar measurements, J. Geophys. Res., 115, D21203, doi:10.1029/2010JD014139, 2010.

Volten, H., Muñoz, O., Rol, E., de Haan, J. F., Vassen, W., Hovenier, J. W., Muinonen, K., and Nousiainen, T.: Scattering matrices of mineral aerosol particles at 441.6 and $632.8 \mathrm{~nm}$, J. Geophys. Res., 106, 17375-17401, doi:10.1029/2001JD900068, 2001.

Wiegner, M., Gasteiger, J., Kandler, K., Weinzierl, B., Rasp, K., Esselborn, M., Freudenthaler, V., Heese, B., Toledano, C., Tesche, M., and Althausen, D.: Numerical simulations of optical properties of Saharan dust aerosols with emphasis on lidar applications, Tellus, 61B, 180-194, 2009.

Wiegner, M., Groß, S., Freudenthaler, V., Schnell, F., and Gasteiger, J.: The May/June 2008 Saharan dust event over Munich: Intensive aerosol parameters from lidar measurements, J. Geophys. Res., 116, D23213, doi:10.1029/2011JD016619, 2011.

Winker, D. M. and Osborn, M. T.: Preliminary analysis of observations of the Pinatubo volcanic cloud with a polarization-sensitive lidar, Geophys. Res. Lett., 19, 171-174, 1992.

Winker, D. M., Vaughan, M. A., Omar, A., Hu, Y., Powell, K. A., Liu, Z., Hunt, W. H., and Young, S. A.: Overview of the CALIPSO Mission and CALIOP Data Processing Algorithms, J. Atmos. Ocean. Tech., 26, 2310-2323, 2009.

Winker, D. M., Pelon, J., Coakley Jr., J. A., Ackerman, S. A., Charlson, R. J., Colarco, P. R., Flamant, P., Fu, Q., Hoff, R. M., Kittaka, C., Kubar, T. L., Le Treut, H., McCormick, M. P., Megie, G., Poole, L., Powell, K., Trepte, C., Vaughan, M. A., and Wielicki, B. A.: THE CALIPSO Mission Global 3D View of Aerosols and Clouds, B. Am. Meteor. Soc., 91, 1211-1229, 2010.

Wise M. E., Biskos, G., Martin, S. T., Russell, L. M., and Buseck, P. R.: Phase Transitions of Single Salt Particles Studied Using a Transmission Electron Microscope with an Environmental Cell, Aerosol Sci. Technol., 39, 849-856, 2005.

Zhang, D.: Effect of sea salt on dust settling to the ocean, Tellus, 60B, 641-646, 2008. 